\title{
Dichotomous Role of Plasmin in Regulation of Macrophage Function after Acetaminophen Overdose
}

\author{
Katherine Roth, ${ }^{* \dagger \ddagger}$ Jenna Strickland, ${ }^{* \dagger}$ Nikita Joshi, ${ }^{\dagger \S}$ Meihong Deng, ${ }^{\llbracket}$ Rebekah C. Kennedy, ${ }^{* \dagger}$ Cheryl E. Rockwell, ${ }^{* \dagger \ddagger}$
} James P. Luyendyk, ${ }^{\dagger \S}$ Timothy R. Billiar, ${ }^{\Uparrow}$ and Bryan L. Copple ${ }^{* \dagger \dagger}$

From the Department of Pharmacology and Toxicology, ${ }^{*}$ the Institute for Integrative Toxicology, ${ }^{\dagger}$ the Cell and Molecular Biology Program, ${ }^{\ddagger}$ and the Pathobiology and Diagnostic Investigation, ${ }^{\S}$ Michigan State University, East Lansing, Michigan; and the Department of Surgery, ${ }^{\natural}$ University of Pittsburgh, Pittsburgh, Pennsylvania

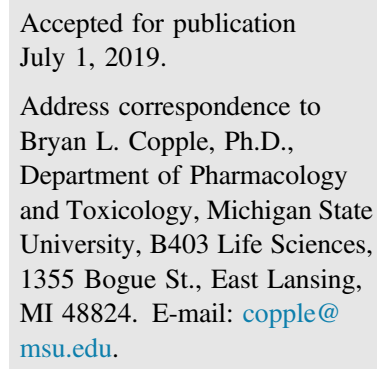

\begin{abstract}
Kupffer cells and monocyte-derived macrophages are critical for liver repair after acetaminophen (APAP) overdose. These cells produce promitogenic cytokines and growth factors, and they phagocytose dead cell debris, a process that is critical for resolution of inflammation. The factors that regulate these dynamic functions of macrophages after APAP overdose, however, are not fully understood. We tested the hypothesis that the fibrinolytic enzyme, plasmin, is a key regulator of macrophage function after APAP-induced liver injury. In these studies, inhibition of plasmin in mice with tranexamic acid delayed up-regulation of proinflammatory cytokines after APAP overdose. In culture, plasmin directly, and in synergy with high-mobility group B1, stimulated Kupffer cells and bone marrow-derived macrophages to produce cytokines by a mechanism that required NF- $\kappa \mathrm{B}$. Inhibition of plasmin in vivo also prevented trafficking of monocyte-derived macrophages into necrotic lesions after APAP overdose. This prevented phagocytic removal of dead cells, prevented maturation of monocyte-derived macrophages into F4/80-expressing macrophages, and prevented termination of proinflammatory cytokine production. Our studies reveal further that phagocytosis is an important stimulus for cessation of proinflammatory cytokine production as treatment of proinflammatory, monocyte-derived macrophages, isolated from APAP-treated mice, with necrotic hepatocytes decreased expression of proinflammatory cytokines. Collectively, these studies demonstrate that plasmin is an important regulator of macrophage function after APAP overdose. (Am J Pathol 2019, 189: 1986-2001; https://doi.org/10.1016/j.ajpath.2019.07.003)
\end{abstract}

Acetaminophen (APAP) is a commonly used overthe-counter analgesic and antipyretic that is safe when taken as directed. Unfortunately, however, thousands of hospitalizations and hundreds of deaths occur each year due to either intentional or accidental overdose. ${ }^{1}$ When taken at high doses, APAP produces hepatocellular injury that can rapidly progress to acute liver failure (ALF), a condition with a high rate of mortality. ${ }^{2}$ Pharmacologic therapies for APAP overdose are limited to $\mathrm{N}$-acetyl-cysteine, which is highly efficacious when administered early after APAP ingestion. ${ }^{3,4}$ Unfortunately, many patients do not seek medical attention until liver injury is extensive and $\mathrm{N}$-acetyl-cysteine is no longer effective.
Monocytes and macrophages play a key role in liver repair after APAP overdose. Early after the onset of liver injury, Kupffer cells, the resident macrophages of the liver, become activated and secrete proinflammatory cytokines that recruit several immune cell types, including proinflammatory monocytes, to the liver. ${ }^{5}$ The recruited

Supported by NIH grants DK103895 (B.L.C.) and DK105099 (J.P.L.); and the US Department of Agriculture National Institute of Food and Agriculture (J.P.L.).

Disclosures: None declared.

Current address of N.J., Division of Pulmonary and Critical Care Medicine, Northwestern University, Feinberg School of Medicine, Chicago, IL. 
monocytes migrate within the hepatic sinusoids and ultimately traffic into the necrotic lesions, where they produce cytokines that amplify the immune response and produce toxic molecules aimed at killing invading pathogens. ${ }^{6-8}$ On resolution of the injury, the proinflammatory monocytes phagocytose dead cells and differentiate into prorepair macrophages that produce anti-inflammatory cytokines and proregenerative growth factors. ${ }^{6,8}$ The mechanisms that regulate monocyte/macrophage trafficking, cytokine secretion, and phagocytosis in the context of APAP-induced liver injury are not fully understood. A full understanding of these mechanisms is important, as recent studies in patients and in mouse models indicate that cytokine production and phagocytosis are dysregulated in ALF. ${ }^{9-11}$ These studies raise the intriguing possibility that monocyte/macrophage dysfunction may contribute to failed recovery of liver function in some APAP overdose patients. Accordingly, greater insight into the mechanisms that regulate monocyte/macrophage function could provide insight into the cause of monocyte/macrophage dysregulation and failed liver regeneration in certain ALF patients.

Several studies have demonstrated that the fibrinolytic enzyme, plasmin, regulates various monocyte and macrophage functions. For instance, plasmin regulates macrophage recruitment to the lungs and peritoneum during inflammatory episodes, ${ }^{12,13}$ and plasmin stimulates macrophage phagocytosis and cytokine production in vitro. ${ }^{14-16}$ In the liver, deficiency in plasminogen, the zymogen for plasmin, impairs macrophage recruitment after stab injury and prevents clearance of dead cells after carbon tetrachloride-induced liver injury. ${ }^{17,18}$ Although these studies indicate a key role for plasmin in regulation of macrophage function, it is not known whether plasmin regulates macrophage function after APAP overdose. Accordingly, in the following studies, the hypothesis was tested that plasmin is critical for regulation of macrophage function after APAP overdose.

\section{Materials and Methods}

\section{In Vivo Treatments}

Male C57BL/6 (Jackson Laboratories, Bar Harbor, ME), annexin A2 knockout, protease-activated receptor-1 (PAR-1) knockout mice, and hepatocyte-specific high mobility group box 1 (HMGB1) knockout mice, aged 6 to 12 weeks, were used for all studies. Annexin A2 knockout [generously provided by Dr. Russel S. Taichman (University of Michigan, Ann Arbor, MI)] and PAR-1 knockout mice were described previously. ${ }^{19,20}$ Hepatocyte-specific HMGB1 knockout mice were described previously. ${ }^{21}$ Mice were housed in a 12-hour light/dark cycle under controlled temperature $\left(18^{\circ} \mathrm{C}\right.$ to $\left.21^{\circ} \mathrm{C}\right)$ and humidity. Food (Rodent Chow; Harlan-Teklad, Indianapolis, IN) and tap water were allowed ad libitum.

For in vivo treatment, mice were fasted for approximately 16 hours before APAP injection. Mice were injected with
$300 \mathrm{mg} / \mathrm{kg}$ APAP (Sigma-Aldrich, St. Louis, MO) or sterile saline by i.p. injection, and food was returned immediately after APAP challenge.

For studies using tranexamic acid, mice were injected with $1200 \mathrm{mg} / \mathrm{kg}$ tranexamic acid (Spectrum Chemical, New Brunswick, NJ) or endotoxin-free water vehicle (G Biosciences, St. Louis, MO) beginning 2 hours after APAP treatment. Tranexamic acid was administered twice daily after the initial treatment.

\section{Sample Collection}

Mice were anesthetized using Fatal-Plus Solution (Vortech Pharmaceuticals, Dearborn, MI). Blood was collected from the inferior vena cava, and serum was collected. The activity of alanine aminotransferase was measured in the serum by using the Infinity ALT (GPT) Liquid Reagent (Thermo-Fisher Scientific, Waltham, MA). The livers were removed, and a portion was fixed in $10 \%$ neutral-buffered formalin. The tissues were embedded in paraffin, and sections of liver were stained with hematoxylin and eosin, proliferating cell nuclear antigen, or lymphocyte antigen 6G (Ly6G antibody). The area of necrosis was quantified, as described by us previously. ${ }^{22}$ Additional pieces of liver were homogenized in TRIzol Reagent (Thermo-Fisher Scientific) for RNA isolation.

\section{Isolation and Culture of Cells}

To isolate Kupffer cells, livers from C57BL/6 mice were perfused and digested with collagenase (Collagenase $\mathrm{H}$; Sigma-Aldrich), as described previously. ${ }^{23}$ After removal of hepatocytes by centrifugation, the nonparenchymal cells were centrifuged at $300 \times g$ for 10 minutes. A total of $1 \times 10^{8}$ nonparenchymal cells were resuspended in $60 \mu \mathrm{L}$ of MACS Buffer (2.5 g bovine serum albumin, $0.416 \mathrm{~g}$ EDTA, and $500 \mathrm{~mL}$ phosphate-buffered saline) containing $12 \mu \mathrm{L}$ biotinylated anti-F4/80 antibody (Miltenyi Biotec, Bergisch Gladbach, Germany). The cell suspension was incubated for 10 minutes at $4{ }^{\circ} \mathrm{C}$ and then washed by adding $10 \mathrm{~mL}$ of MACS buffer and centrifugation $(300 \times g$ for 10 minutes). Streptavidin microbeads (Miltenyi Biotec), diluted 1:10 in $60 \mu \mathrm{L}$ of MACs buffer, were added to the nonparenchymal pellet. Cells were resuspended and incubated at $4^{\circ} \mathrm{C}$ for 10 minutes and then washed by adding $10 \mathrm{~mL}$ of MACS buffer and centrifugation ( $300 \times g$ for 10 minutes). The pellet was resuspended with $500 \mu \mathrm{L}$ MACS buffer and applied to MACS LS columns (Miltenyi Biotec). The column was rinsed three times with $3 \mathrm{~mL}$ MACS buffer. Kupffer cells were collected by removing the column from the midiMACS Separator (Miltenyi Biotec) and rinsing the column with $5 \mathrm{~mL}$ of MACS buffer.

For generation of bone marrow-derived macrophages (BMMs), bone marrow was isolated from the femurs of mice and cultured in RPMI 1640 medium containing $10 \%$ fetal bovine serum, penicillin/streptomycin, and 10 $\mathrm{ng} / \mathrm{mL}$ recombinant mouse macrophage colony-stimulating 
factor (BioLegend, San Diego, CA). On day 4 of culture, the medium was replaced with fresh plating medium. Cells were harvested 7 days after plating.

Kupffer cells and bone marrow-derived macrophages were plated in serum-free RPMI 1640 medium. The cells were treated with $100 \mathrm{nmol} / \mathrm{L}$ mouse plasmin (Hematologic Technologies, Essex Junction, VT) or human plasma-derived plasminogen [R\&D Systems, Minneapolis, $\mathrm{MN} ;<1.0$ endotoxin unit (EU) per $\mathrm{mg}$ of protein]. For studies in which cells were cultured with both plasmin and HMGB1, cells were treated with plasmin for 10 minutes, followed by addition of $100 \mathrm{ng} / \mathrm{mL}$ recombinant human HMGB1 (R\&D Systems; <1.0 EU per mg of protein). For in vitro studies with tranexamic acid, cells were treated with $1 \mathrm{mmol} / \mathrm{L}$ tranexamic acid, followed by treatment with plasmin. For inactivation of plasmin, plasmin was incubated with $1 \mu \mathrm{mol} / \mathrm{L}$ D-Val-Phe-Lys chloromethyl ketone (Sigma-Aldrich) for 30 minutes at $37^{\circ} \mathrm{C}$ before addition to cells.

Ly6 $\mathrm{C}^{\text {hi }}$ monocytes were isolated from the livers of mice treated with $300 \mathrm{mg} / \mathrm{kg}$ APAP for 24 hours. After removal of hepatocytes, nonparenchymal cells were centrifuged at $300 \times g$ for 10 minutes. ACK Buffer (Lonza, Basel, Switzerland) was used to lyse red blood cells. The nonparenchymal fraction was centrifuged at $300 \times g$ for 5 minutes and resuspended in $60 \mu \mathrm{L}$ of biotin-labeled antiLy6C mouse antibody (Miltenyi Biotec) diluted 1:10 in MACs buffer and incubated at $4{ }^{\circ} \mathrm{C}$ for 10 minutes. Next, the cells were rinsed using $10 \mathrm{~mL}$ MACs buffer and centrifuged at $300 \times g$ for 10 minutes. Streptavidin microbeads (Miltenyi Biotec), diluted 1:10 in $60 \mu \mathrm{L}$ of MACs buffer, were added to the nonparenchymal cell pellet. Cells were resuspended and incubated at $4{ }^{\circ} \mathrm{C}$ for 10 minutes. After incubation, the cells were added to MACS LS columns, as described above. Ly6C ${ }^{\text {hi }}$ monocytes, collected from the column, were cultured in serum-free Williams' Medium E (Sigma-Aldrich) containing penicillin/streptomycin.

Hepatocytes were isolated from the livers of C57BL/6 mice, as described by us previously. ${ }^{23}$ The cells were diluted to $2.5 \times 10^{5}$ in serum-free Williams' Medium E and then made necrotic by three cycles of freeze-thaw at $-80^{\circ} \mathrm{C}$. Cell lysis was confirmed by trypan blue staining and was $100 \%$.

\section{Limulus Amebocyte Lysate Assay}

Endotoxin was measured in the plasmin, RPMI 1640 medium (Sigma-Aldrich), and phosphate-buffered saline (Sigma-Aldrich) by using the limulus amebocyte lysate assay, following the manufacturer's recommendations (Thermo-Fisher Scientific). The following concentrations of endotoxin were measured: RPMI 1640 medium, $0.16 \mathrm{EU} /$ $\mathrm{mL}$; phosphate-buffered saline, $0.11 \mathrm{EU} / \mathrm{mL}$; plasmin, 0.13 $\mathrm{EU} / \mathrm{mL}$. These concentrations of endotoxin are below those needed to stimulate up-regulation of tumor necrosis factor- $\alpha$ $(\mathrm{TNF}-\alpha)$ in monocytes and macrophages. ${ }^{24}$

\section{Immunohistochemistry}

Immunofluorescence was used to detect F4/80 and CD68, as described by us previously. ${ }^{22}$ Briefly, frozen liver sections ( $8 \mu \mathrm{m}$ thick) were fixed in $4 \%$ formalin for 10 minutes, followed by blocking in $10 \%$ goat serum. The sections were then incubated with rat anti-F4/80 antibody (Bio-Rad, Hercules, CA) diluted 1:500 or rat anti-CD68 antibody (Bio-Rad) diluted 1:500. The sections were then incubated with goat anti-rat secondary antibodies conjugated to Alexa Fluor 488 or 594 (diluted 1:500; Thermo-Fisher Scientific).

Immunofluorescence was also used to detect Ly6C (green) and F4/80 (red) in cultured Ly6 $\mathrm{C}^{\mathrm{hi}} \mathrm{F} 4 / 80^{\text {neg }}$ monocytes. The cells were fixed in $10 \%$ formalin, followed by incubation with Fc blocking buffer (BD Biosciences, San Jose, CA; diluted 1:20) for 10 minutes at $4^{\circ} \mathrm{C}$. The cells were then incubated overnight at $4^{\circ} \mathrm{C}$ with either anti-Ly6C antibody conjugated to Alexa 488 or anti-F4/80 antibody conjugated to Alexa 594 antibodies (diluted 1:50; BioLegend).

Neutrophils were detected in sections of formalin-fixed, paraffin-embedded liver by detecting Ly6G (clone 1A8; BioXCell, West Lebanon, NH). Proliferating hepatocytes were quantified by detecting proliferating cell nuclear antigen antibody from Abcam (Cambridge, UK).

\section{Western Blot Analysis}

Macrophages were lysed with radioimmunoprecipitation assay buffer. Protein was separated onto a $4 \%$ to $20 \%$ polyacrylamide gel (Bio-Rad) and transferred to a polyvinylidene difluoride membrane. The membranes were incubated with anti-phosphorylated (phospho) p38, anti-total p38, anti-phospho-extracellular signal-regulated kinase 1/2, anti-total extracellular signal-regulated kinase $1 / 2$,

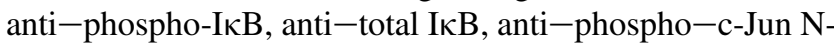
terminal kinase (JNK), anti-total JNK, anti-phospho-AKT, or anti-total AKT using the recommended dilutions (all antibodies from Cell Signaling Technology, Danvers, MA). Membranes were incubated with secondary antibody conjugated with horseradish peroxidase (Sigma-Aldrich), and protein bands were detected using Clarity Western ECL Substrate (Bio-Rad) on a LI-COR Odyssey Fc (LI-COR Biosciences, Lincoln, NE).

\section{Flow Cytometry}

Nonparenchymal cells and purified Ly6 $\mathrm{C}^{\mathrm{hi}}$ monocytes were isolated using protocols described above. After isolation, cells were washed and resuspended with FACS buffer (phosphate-buffered saline, $1 \%$ fetal bovine serum; BioLegend). The cells were then incubated with $\mathrm{Fc}$ blocking buffer (BD Biosciences; diluted 1:20) for $10 \mathrm{mi}-$ nutes at $4^{\circ} \mathrm{C}$. Next, cells were rinsed and centrifuged at 300 $\times g$ for 5 minutes to pellet. The cells were then incubated with anti-F4/80/Alexa Fluor 488 and anti-Ly6C/ phosphatidylethanolamine for 30 minutes at $4^{\circ} \mathrm{C}$. In a 
separate study, the cells were incubated with anti-CD45/ phosphatidylethanolamine/Cy7, anti-CD68/Alexa Fluor 594, and anti-F4/80/Alexa Fluor 488 for 30 minutes at $4{ }^{\circ} \mathrm{C}$. All antibodies were purchased from BioLegend. After incubation, cells were washed twice and fixed in formalin (Sigma-Aldrich) for 15 minutes at $4^{\circ} \mathrm{C}$. After cells were fixed, they were washed twice and resuspended using FACS buffer. The fluorescence was then detected using an Attune NxT flow cytometer from Life Technologies (Carlsbad, $\mathrm{CA}$ ), and the signal was quantified using Attune NxT software version 3.1 (Life Technologies).

\section{Real-Time PCR}

RNA was isolated from liver samples using TRIzol Reagent or from cell culture samples by using the E.Z.N.A. Total RNA Kit I (Omega Bio-Tek, Norcross, GA), according to manufacturer's instructions. Real-time PCR was performed, as described by us previously. ${ }^{23}$ The following primer sequences were used: TNF- $\alpha, 5^{\prime}$-AGGGTCTGGGCCATAGAACT-3' (forward) and 5'-CCACCACGCTCTTCTGTCTAC-3' (reverse); Cxcl1, 5'-TGGCTGGGATTCACCTCAAG$3^{\prime}$ (forward) and $5^{\prime}$-GTGGCTATGACTTCGGTTTGG-3' (reverse); Cxcl2, 5'-CTCAGACAGCGAGGCACATC-3' (forward) and 5'-CCTCAACGGAAGAACCAAAGAG$3^{\prime}$ (reverse); chemokine (C-C motif) ligand (Ccl) 2, 5'CCTGCTGTTCACAGTTGCC-3' (forward) and $5^{\prime}$ ATTGGGATCATCTTGCTGGT- $3^{\prime}$ (reverse); and 60S ribosomal protein L13a, 5'-GACCTCCTCCTTTCCCAGGC-3' (forward) and 5'-AAGTACCTGCTTGGCCACAA-3' (reverse).

\section{Luminex Immunoassay}

Protein levels were measured in cell culture supernatants and serum samples by using the Bio-Plex Pro Assay Kit (Bio$\mathrm{Rad})$. The samples were analyzed on a Luminex 200 System (Luminex Corp., Austin, TX).

\section{Statistical Analysis}

Results are presented as the means + SEM. Data were analyzed by a one- or two-way analysis of variance, where appropriate. Data expressed as a percentage were transformed by arcsine square root before analysis. Comparisons among group means were made using the Student-NewmanKeuls test. The criterion for significance was $P<0.05$ for all studies. A minimum of an $n=5$ per group was used for in vivo studies. In vitro studies were repeated a minimum of three times with cells isolated from separate groups of mice.

\section{Results}

Plasmin Inhibition Suppresses Early Cytokine Induction after APAP Overdose

To investigate the role of plasmin in regulation of monocyte and macrophage function after APAP overdose, plasmin was inhibited with the US Food and Drug Administration-approved plasmin inhibitor, tranexamic acid. Mice were treated with tranexamic acid beginning 2 hours after APAP administration to prevent interference with APAP metabolism. Treatment of mice with APAP and vehicle caused a time-dependent increase in serum alanine aminotransferase activity that was unaffected by cotreatment with tranexamic acid (Figure 1A). By 8 hours after treatment with APAP, mRNA levels of the proinflammatory cytokines and chemokines, TNF- $\alpha, \mathrm{Cxcl1}$, and $\mathrm{Cxcl} 2$, were increased (Figure 1, B-D). Cotreatment with tranexamic acid completely prevented up-regulation of all three cytokines/ chemokines (Figure 1, B-D). Similarly, serum levels of Ccl2 protein, a monocyte/macrophage chemokine, were lower in mice treated with APAP and tranexamic acid (Figure 1E).

\section{Plasmin Stimulates Proinflammatory Cytokine Production by Kupffer Cells and Bone Marrow-Derived Macrophages}

To determine the mechanism by which plasmin stimulates cytokine induction after APAP overdose, we first investigated whether plasmin directly increases expression of cytokines in macrophages. To investigate this, Kupffer cells and BMMs were isolated from wild-type C57BL/6 mice and treated with $100 \mathrm{nmol} / \mathrm{L}$ plasmin. This concentration of plasmin is pathologically relevant as the plasma concentration of plasminogen, the zymogen for plasmin, is approximately $1.4 \mu \mathrm{mol} / \mathrm{L}$ in mice. Treatment of Kupffer cells (Figure 2, A-C) and BMMs (Figure 2, E and F) with plasmin increased expression of TNF- $\alpha, \mathrm{Cxcl} 1$, and Cxcl2. In addition, plasmin increased production of $\mathrm{Ccl} 2$ protein by BMMs (Figure 2G) and stimulated the formation of extensive pseudopodia, a characteristic of activated macrophages (Figure 2D). Up-regulation of cytokines (Figure 2, H and I) and formation of pseudopodia (data not shown) were inhibited by the plasmin inhibitors, D-Val-Phe-Lys chloromethyl ketone (Figure 2H) and tranexamic acid (Figure 2I), indicating a need for plasmin enzyme activity. Similar to plasmin, plasminogen caused a dose-dependent increase in cytokine mRNA levels (Figure 2, J-L).

\section{Activation of Signal Transduction Pathways in Plasmin-Treated Macrophages}

Plasmin activated $\mathrm{p} 38$, extracellular signal-regulated kinase $1 / 2$, and Jnk in BMMs at 2 hours (Figure 3A). Furthermore, plasmin treatment increased phosphorylation of $\mathrm{I} \kappa \mathrm{B}$, indicating activation of NF- $\kappa \mathrm{B}$ (Figure 3A). Interestingly, plasmin decreased Akt phosphorylation in BMMs (Figure 3A). Pretreatment of BMMs with the I $\kappa$ B kinase 2 inhibitor, TPCA1, completely prevented up-regulation of TNF- $\alpha$ by plasmin (Figure 3B). By contrast, inhibition of p38 signaling (SB203580) (Figure 3C), Jnk signaling (SP600125) (Figure 3D), or extracellular signal-regulated kinase 1/2 signaling (PD98059) (Figure 3E) did not affect 

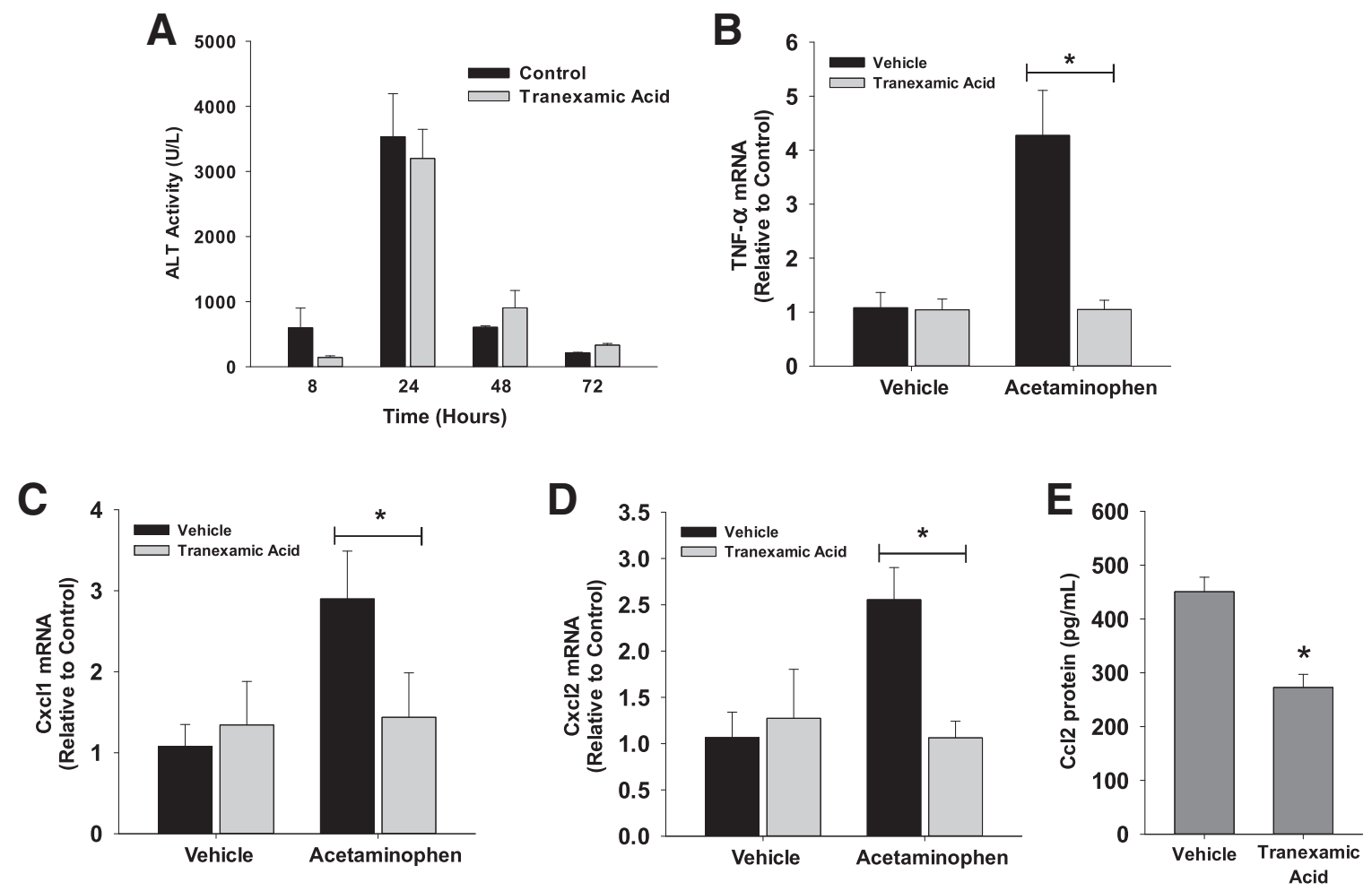

Figure 1 Mice were treated with $300 \mathrm{mg} / \mathrm{kg}$ acetaminophen (APAP), followed by treatment with tranexamic acid, as detailed in Materials and Methods. A: Alanine aminotransferase (ALT) activity was measured at the indicated times. B-D: mRNA levels of tumor necrosis factor (TNF)- $\alpha$ (B), Cxcl1 (C), and Cxcl2 (D) were measured 8 hours after APAP treatment. E: Chemokine (C-C motif) ligand (Ccl2) protein was measured in the serum. Data are expressed as means \pm SEM $(\mathbf{A}-\mathbf{E}) . n=5$ mice per group $(\mathbf{A}-\mathbf{E}) .{ }^{\star} P<0.05$ versus vehicle.

induction of TNF- $\alpha$ by plasmin. Similar results were observed for Cxcl1 and Cxcl2 (data not shown).

Studies have indicated that plasmin may stimulate signaling in cells by activation of either annexin A2 or PAR-1. ${ }^{25,26}$ To investigate this in macrophages, BMMs were isolated from either annexin A2 or PAR-1 knockout mice. Neither loss of annexin A2 nor PAR-1 affected upregulation of cytokines by plasmin (Figure $3, \mathrm{~F}-\mathrm{K}$ ).

\section{HMGB1 Enhances Activation of Macrophages by Plasmin}

Recent studies have revealed that the damage-associated molecular pattern molecule, HMGB1, contributes to macrophage activation in the liver after APAP overdose. ${ }^{27}$ To examine this further, Kupffer cells and BMMs were isolated and treated with either recombinant HMGB1 or necrotic primary mouse hepatocytes, which contain HMGB1. Neither HMGB1 nor necrotic hepatocytes increased expression of TNF- $\alpha$ in Kupffer cells or BMMs (Figure 4, A and B). As demonstrated earlier, however, plasmin increased expression of TNF- $\alpha$ in both cell types. Next, Kupffer cells were treated with increasing concentrations of HMGB1. Concentrations of HMGB1 as high as $500 \mathrm{ng} / \mathrm{mL}$ did not increase expression of TNF- $\alpha$ (Figure 4C). By comparison, blood levels of HMGB1 are approximately $4 \mathrm{ng} / \mathrm{mL}$ in APAP-induced ALF patients and approximately $175 \mathrm{ng} / \mathrm{mL}$ in mice treated with a high dose of APAP $(530 \mathrm{mg} / \mathrm{kg}){ }^{28}$ Because of the apparent importance of both plasmin and HMGB1 in macrophage activation in vivo, the hypothesis that these two mediators interact to fully activate macrophages was tested. Plasmin increased TNF- $\alpha$ and Cxcl1 mRNA levels, whereas HMGB1 alone did not (Figure 4, D and E). Interestingly, HMGB1 synergistically enhanced up-regulation of these cytokines by plasmin, supporting an interaction between these inflammatory mediators. In addition to mRNA levels, $\mathrm{Ccl} 2$ protein levels were synergistically increased by the combination of plasmin and HMGB1 (Figure 4F). Similar to recombinant HMGB1, necrotic hepatocytes from wild-type mice, which did not activate macrophages directly (Figure 4, A and B), enhanced up-regulation of proinflammatory cytokines by plasmin, whereas necrotic hepatocytes from hepatocytespecific HMGB1 knockout mice did not (Figure 4, G-I). Because NF- $\mathrm{KB}$ activation was required for up-regulation of cytokines by plasmin, it was investigated whether it was also required for the interaction between plasmin and HMGB1. TPCA1 substantially prevented up-regulation of TNF- $\alpha$ by the combination of plasmin and HMGB1 (Figure 4J).

Plasmin Inhibition Prevents Removal of Necrotic Cells from the Liver after APAP Overdose

Next, the impact of plasmin inhibition was determined on macrophage function at later times after APAP overdose. 

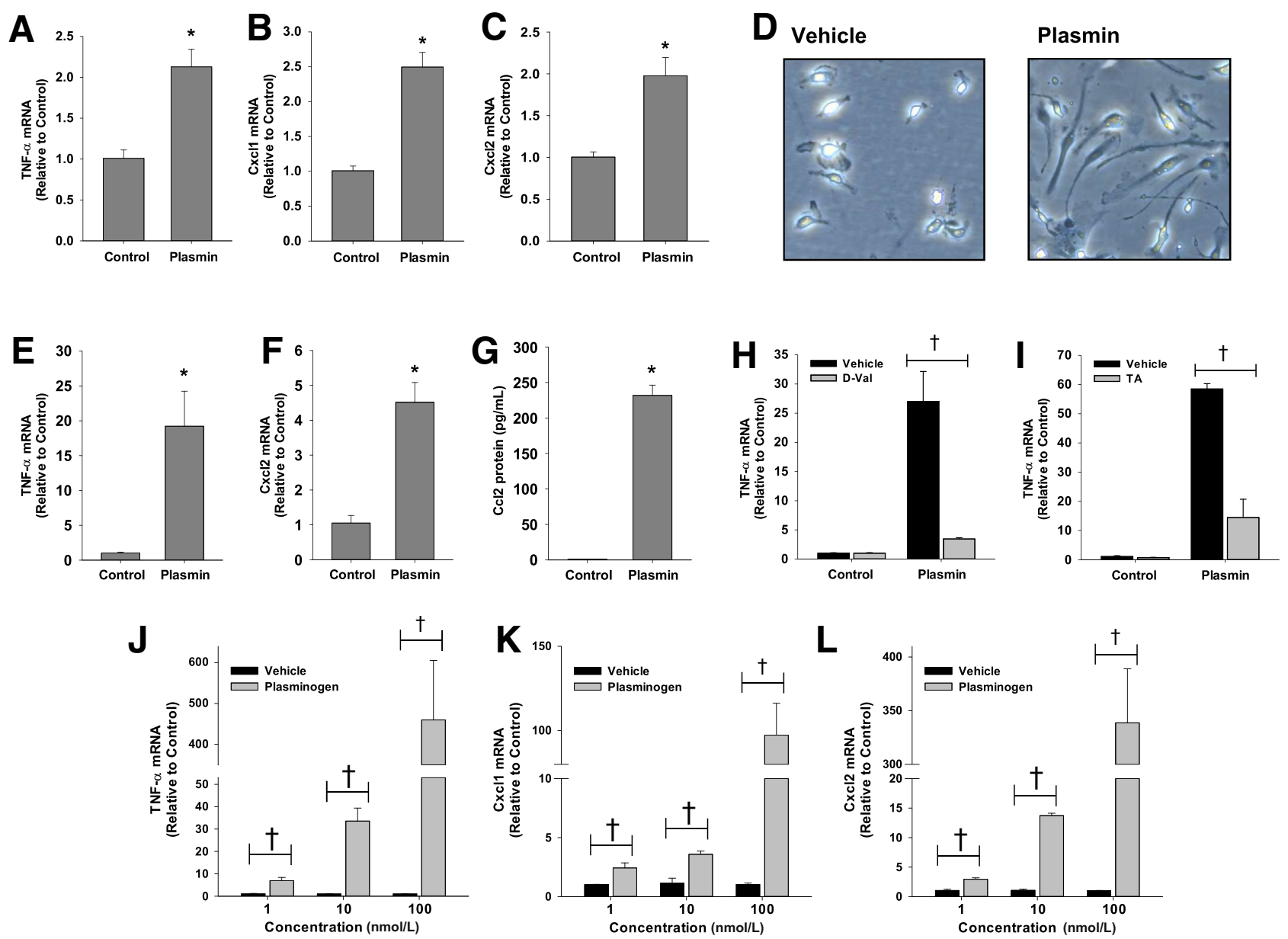

Figure 2 A-C and $\mathbf{E}-\mathbf{G}$ : Kupffer cells $(\mathbf{A}-\mathbf{C})$ and bone marrow-derived macrophages (BMMs; $\mathbf{E}-\mathbf{G}$ ) were treated with $100 \mathrm{nmol} / \mathrm{L}$ plasmin. mRNA levels of the indicated cytokines were measured 6 hours later. D: Photomicrographs of BMMs treated with vehicle or plasmin for 18 hours. $\mathbf{H}$ and I: BMMs were treated with 100 $\mathrm{nmol} / \mathrm{L}$ plasmin in the presence or absence of D-Val-Phe-Lys chloromethyl ketone (D-Val; $\mathbf{H}$ ) or tranexamic acid (TA; I). Tumor necrosis factor (TNF)- $\alpha$ mRNA levels were quantified. J-L: BMMs were treated with vehicle or the indicated concentration of plasminogen. mRNA levels of the indicated cytokines were measured 6 hours later. Data are expressed as means \pm SEM $(\mathbf{A}-\mathbf{C}$ and $\mathbf{E}-\mathbf{L}) . n=3 .{ }^{*} P<0.05$ versus control; ${ }^{\dagger} P<0.05$ versus vehicle. Original magnification, $\times 400(\mathbf{D})$. Ccl, chemokine (C-C motif) ligand.

In mice treated with APAP and vehicle, necrotic cells were cleared from the liver between 48 and 72 hours (Figure 5, A, B, and E). Few necrotic cells remained in the liver 72 hours after treatment with APAP and vehicle (Figure 5B). In striking contrast, inhibition of plasmin with tranexamic acid prevented clearance of necrotic cells from the liver at 72 hours, as indicated by extensive necrosis remaining in the liver (Figure 5, C-E). Interestingly, despite the impact on clearance of necrotic cells, the numbers of proliferating cell nuclear antigen-positive hepatocytes were not affected (Figure 6).

It was previously reported that the complement system is needed for removal of necrotic cells from the liver after carbon tetrachloride. ${ }^{29}$ Accordingly, it was determined whether inhibition of plasmin affected complement deposition in the liver. Fragments of $\mathrm{C} 3$ cleavage were deposited in necrotic regions of liver after APAP overdose (Figure 7, A and C). By 72 hours, the complement-coated necrotic cells were completely removed from the liver (Figure 7, B and E). In mice treated with APAP and tranexamic acid, C3 cleavage products deposited in necrotic regions similar to mice treated with APAP and vehicle, indicating no role for plasmin in activation of the complement system. By contrast, however, the complement-coated necrotic cells were not removed from the livers of mice treated with APAP and tranexamic acid (Figure 7, D and E).

\section{Plasmin Inhibition Prevents Trafficking of Macrophages into Necrotic Lesions after APAP Overdose}

By 48 hours after treatment of mice with APAP and vehicle, CD68-positive monocytes/macrophages filled the necrotic lesions (Figure 8A). In mice treated with APAP and tranexamic acid, however, few CD68-positive monocytes/macrophages trafficked into the necrotic lesions (Figure 8B). In these mice, CD68-positive monocytes/macrophages remained at the periphery of the necrotic lesions. Quantitatively, however, there was no difference in the numbers of CD68-positive monocytes/macrophages in 
A
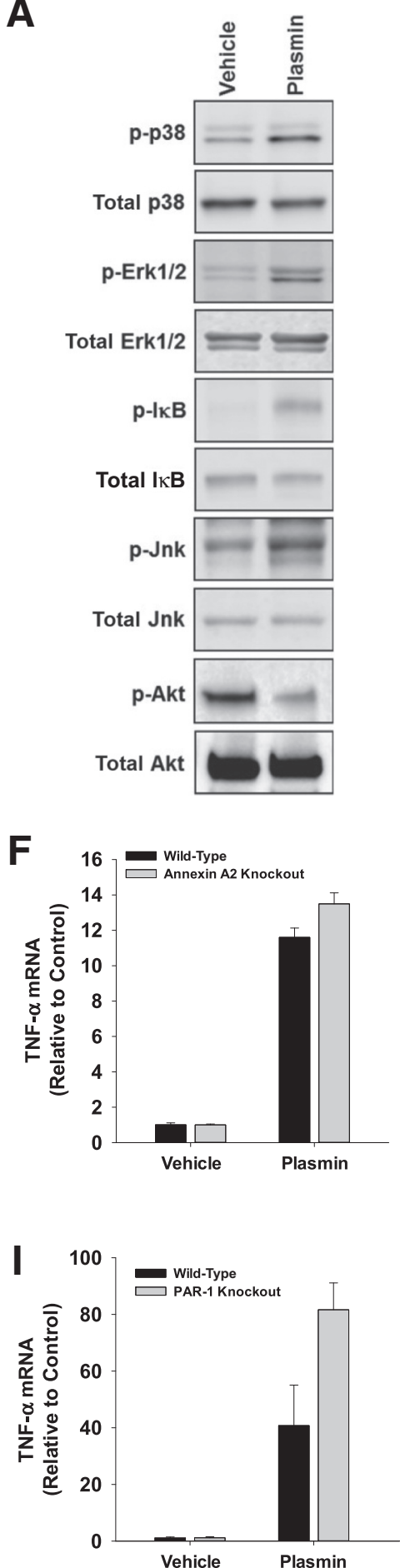

B
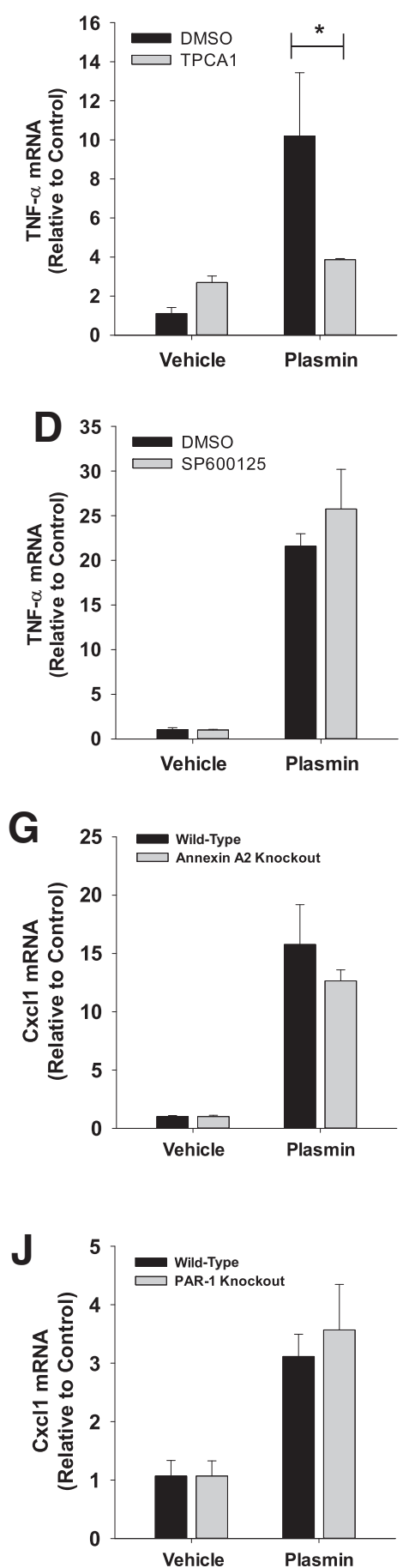

C
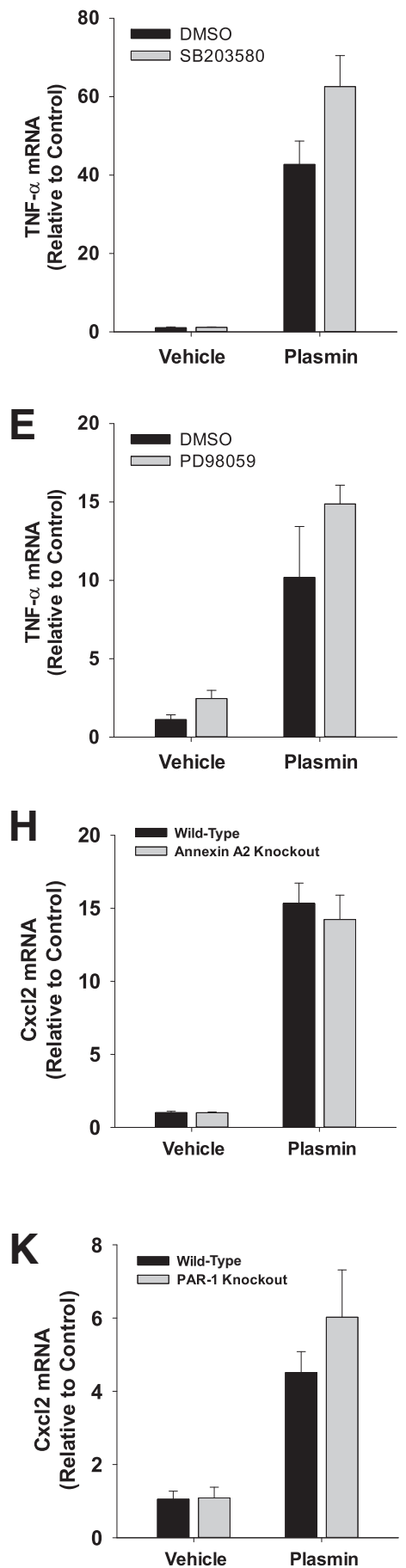

Figure 3 A: Bone marrow-derived macrophages (BMMs) were treated with plasmin for 1 hour. Various signaling pathways were quantified by Western blot analysis. B-E: BMMs were treated with the indicated inhibitor or dimethyl sulfoxide (DMSO), followed by treatment with plasmin 30 minutes later. Tumor necrosis factor (TNF)- $\alpha$ mRNA levels were measured 6 hours later. $\mathbf{F}-\mathbf{K}$ : BMMs were isolated from wild-type and annexin A2 knockout mice (F-H) or wild-type and protease-activated receptor-1 knockout mice $(\mathbf{I}-\mathbf{K})$ and treated with plasmin. mRNA levels of the indicated cytokines were measured 6 hours later. Data are expressed as means $\pm \mathrm{SEM}(\mathbf{B}-\mathbf{K}) . n=3$. ${ }^{*} P<0.05$. Erk, extracellular signal-regulated kinase.

the livers of mice treated with either APAP and vehicle or APAP and tranexamic acid (Figure 8C).

F4/80-positive macrophages were primarily located outside of the necrotic lesions at 48 hours after treatment with either APAP and vehicle or APAP and tranexamic acid (Figure 8, D and E). By 72 hours after treatment with APAP and vehicle, macrophages within the necrotic lesions began to express F4/80 (Figure 8F). By contrast, at 

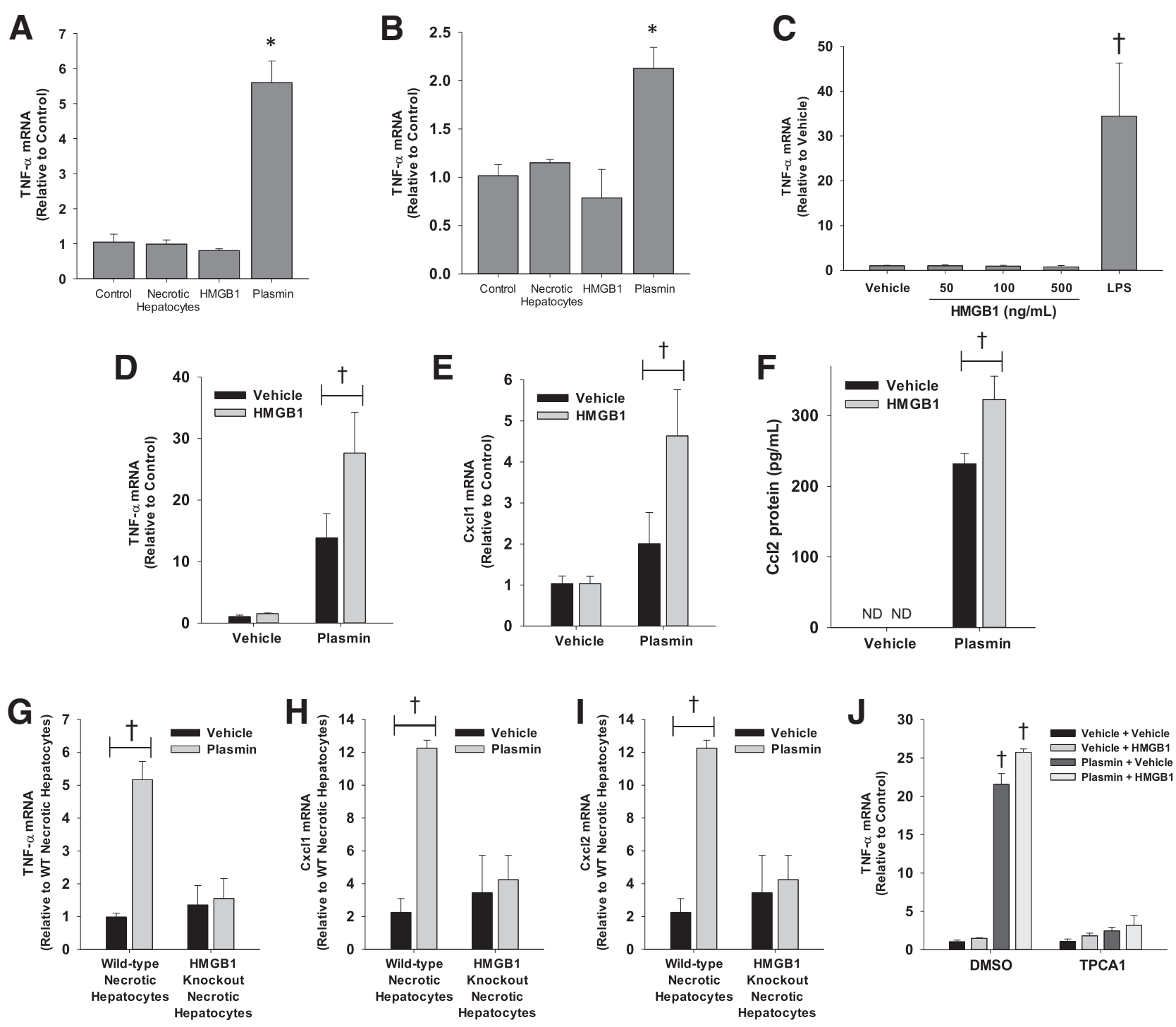

Figure 4 A and B: Bone marrow-derived macrophages (BMMs; A) and Kupffer cells (B) were treated with necrotic hepatocytes, $100 \mathrm{ng} / \mathrm{mL}$ high mobility group box 1 (HMGB1), or $100 \mathrm{nmol} / \mathrm{L}$ plasmin for 6 hours. Significantly different from control cells. C: BMMs were treated with the indicated concentrations of HMGB1. Tumor necrosis factor (TNF)- $\alpha$ mRNA was measured by real-time PCR. D-F: BMMs were treated with plasmin in the presence or absence of HMGB1 for 6 hours. Cytokine mRNAs and chemokine ( $\mathrm{C}-\mathrm{C}$ motif) ligand (Ccl2) protein were quantified. G-I: BMMs were treated with plasmin, followed by treatment with necrotic hepatocytes from wild-type (WT) or hepatocyte-specific HMGB1 knockout mice. J: BMMs were treated with TPCA1 or dimethyl sulfoxide (DMSO) for 30 minutes, followed by treatment with plasmin with and without HMGB1. TNF- $\alpha$ mRNA was measured. Significantly different from cells treated with TPCA1. Data are expressed as means $\pm \mathrm{SEM}(\mathbf{A}-\mathbf{J}) . n=3(\mathbf{A}-\mathbf{J}) .{ }^{*} P<0.05$ versus control $(\mathbf{A}$ and $\mathbf{B}) ;{ }^{\dagger} P<0.05$ versus vehicle $(\mathbf{C}-\mathbf{J})$. ND, not detected.

72 hours after treatment with APAP and tranexamic acid, no macrophages expressing $\mathrm{F} 4 / 80$ were detected within necrotic lesions (Figure 8, G and $\mathrm{H}$ ). To confirm these findings, flow cytometry was used to quantify F4/80 on $\mathrm{CD}^{+} 8^{+}$macrophages. For these studies, liver nonparenchymal cells were isolated from livers and stained for $\mathrm{CD} 45, \mathrm{CD} 68$, and F4/80. F4/80 was quantified on liver nonparenchymal cells that were positive for CD45 and CD68 (Figure 9). Both the intensity of F4/80 staining and the percentage of $\mathrm{F} 4 / 80^{+}$cells were lower in the $\mathrm{CD} 45^{+} \mathrm{CD} 68^{+}$population of macrophages in the livers of mice treated with APAP and tranexamic acid when compared with mice treated with APAP and vehicle (Figure 9).

\section{Effect of Plasmin Inhibition on Neutrophil Accumulation after APAP Overdose}

Because plasmin inhibition impacted the accumulation of macrophages into the necrotic lesions, it was determined whether this impacted accumulation of another immune cell type, neutrophils. Neutrophil accumulation into necrotic lesions was not affected by inhibition of plasmin (Figure 10).

\section{Impact of Plasmin Inhibition on Expression of Cytokines Late after Acetaminophen Overdose}

Studies have suggested that phagocytosis of dead cells by proinflammatory macrophages decreases expression of 
A 48-hour Vehicle

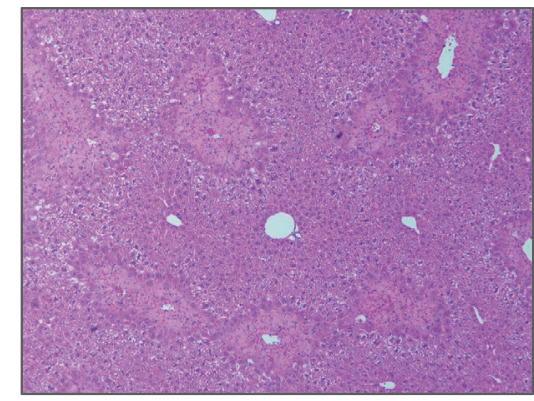

C

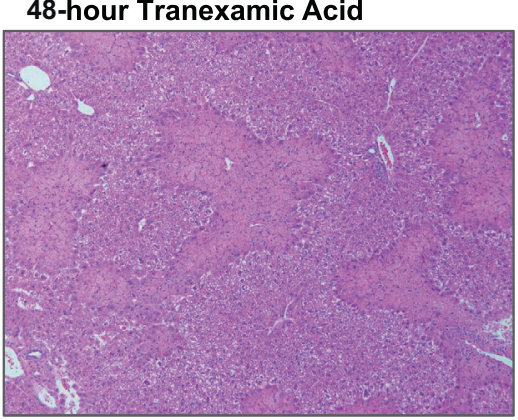

B

72-hour Vehicle

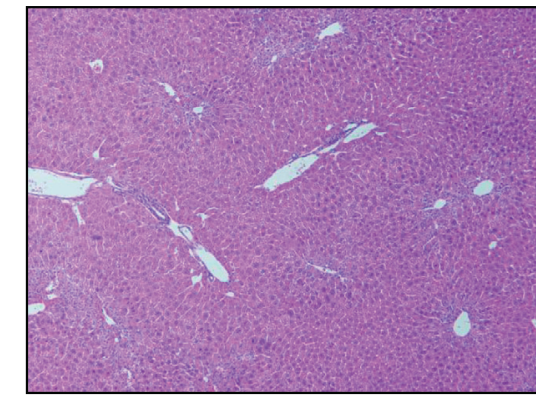

D

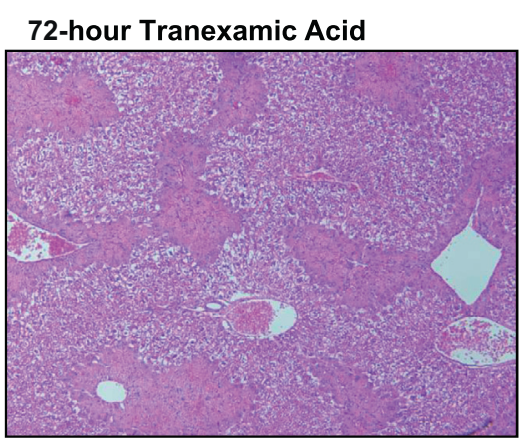

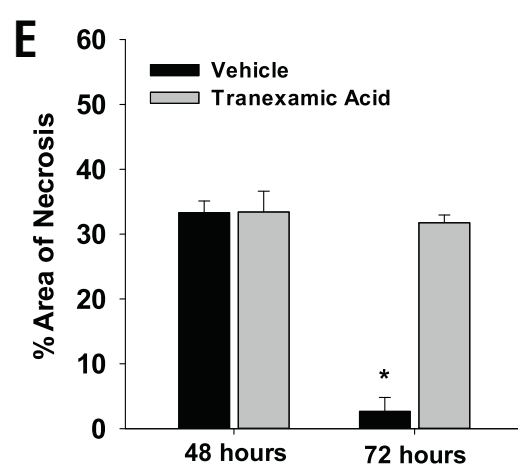

Figure 5 Mice were treated with $300 \mathrm{mg} / \mathrm{kg}$ acetaminophen, followed by treatment with tranexamic acid, as detailed in Materials and Methods. A-D: Photomicrographs of sections of hematoxylin and eosin-stained liver sections. E: Area of necrosis was quantified in sections of liver. Data are expressed as means $\pm \operatorname{SEM}(\mathbf{E}) . n=5$ mice per group $(\mathbf{E}) .{ }^{*} P<0.05$ versus tranexamic acid. Original magnification, $\times 100(\mathbf{A}-\mathbf{D})$.

proinflammatory cytokines, a step that is critical for resolution of inflammation. ${ }^{6,30-32}$ Because there was a failure of monocytes/macrophages to phagocytose dead cells in mice treated with APAP and tranexamic acid, it was determined whether there was a similar failure to terminate inflammatory cytokine production. In mice treated with APAP and vehicle, mRNA levels of TNF- $\alpha$ and $\mathrm{Ccl} 2$ were substantially increased in the liver by 24 hours after treatment (Figure 11). By 72 hours, mRNA levels of both cytokines returned to baseline levels (Figure 11). In mice treated with APAP and tranexamic acid, mRNA levels of TNF- $\alpha$ and Ccl2 were elevated at 24 hours and remained elevated at 72 hours (Figure 11). Similar results were observed for blood levels of Cc12 protein (Figure 11).

\section{Necrotic Hepatocytes Decrease Cytokine Expression in Proinflammatory Monocytes}

The studies above demonstrated that tranexamic acid prevented phagocytosis of dead cells and prevented downregulation of proinflammatory cytokines (Figures 5 and 11). This suggested that phagocytosis may be a stimulus for decreasing cytokine expression in proinflammatory monocytes. To investigate this further in vitro, immunomagnetic bead purification was used to isolate proinflammatory monocytes $\left(\mathrm{Ly} 6 \mathrm{C}^{\text {hi }} \mathrm{F} 4 / 80^{\text {low }}\right.$ ) from the livers of APAP-treated mice. Proinflammatory monocytes rapidly infiltrate the liver after APAP overdose, and studies indicate that these cells are responsible for the clearance of
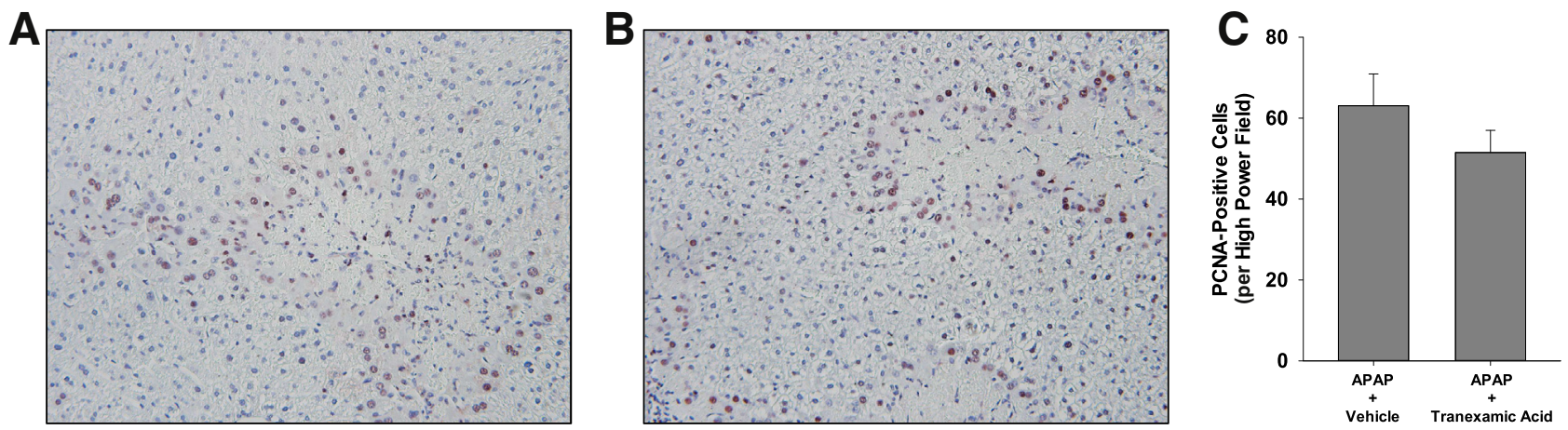

Figure 6 Mice were treated with $300 \mathrm{mg} / \mathrm{kg}$ acetaminophen (APAP), followed by treatment with tranexamic acid for 48 hours, as detailed in Materials and Methods. A and B: Proliferating cell nuclear antigen (PCNA) was detected in liver sections from mice treated with either APAP and water (A) or APAP and tranexamic acid (B). Positive staining appears brown in the photomicrographs. C: The number of PCNA-positive hepatocytes was quantified. Data are expressed as means $\pm \operatorname{SEM}(\mathbf{C}) . n=5$ mice per group (C). Original magnification, $\times 200$ (A and B). 

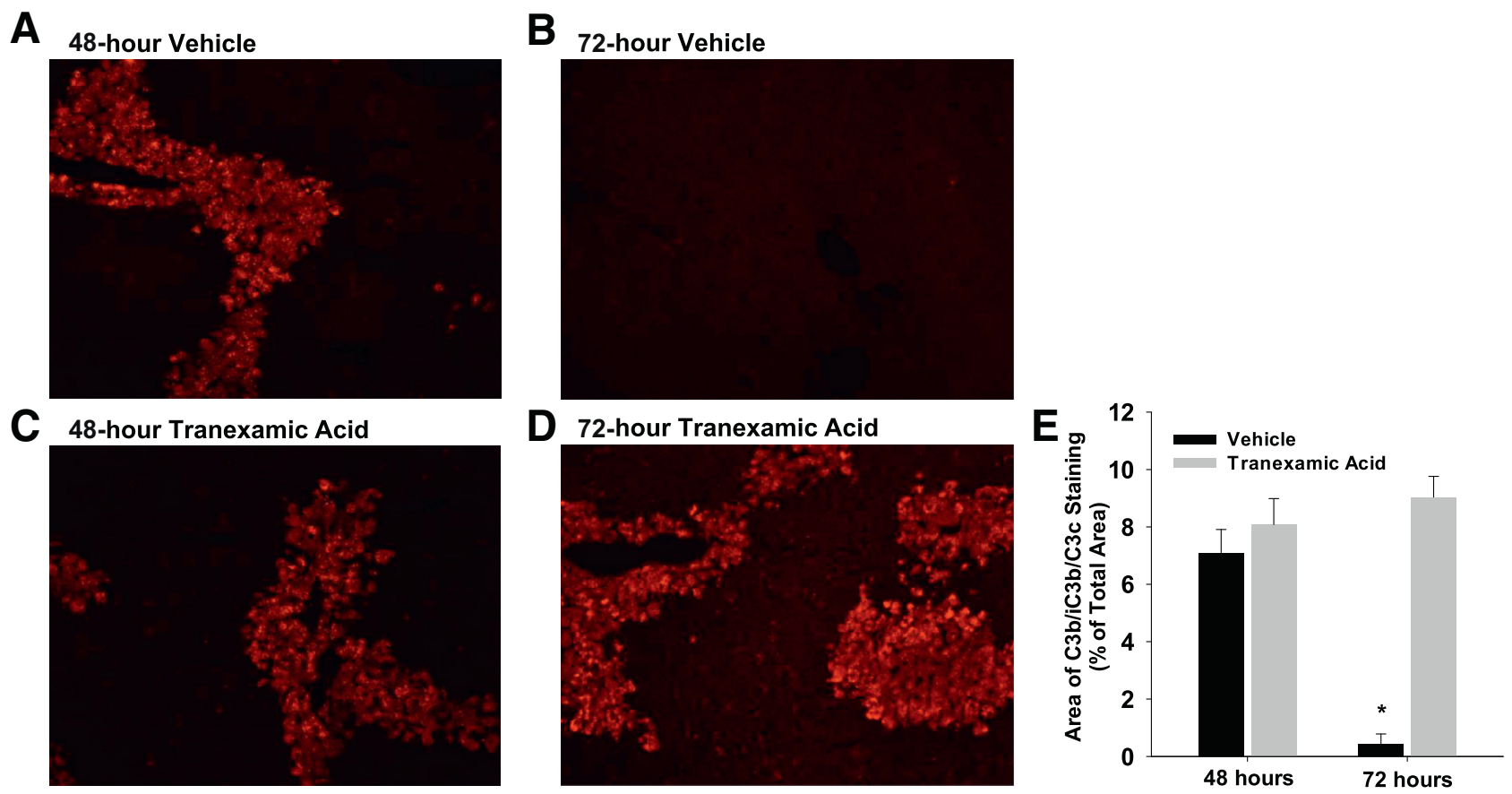

Figure 7 Mice were treated with $300 \mathrm{mg} / \mathrm{kg}$ acetaminophen, followed by treatment with tranexamic acid, as detailed in Materials and Methods. C3b/iC3b/ C3C was detected by immunofluorescence. A-D: Representative photomicrographs of sections of hematoxylin and eosin-stained liver sections. E: Area of $\mathrm{C} 3 \mathrm{~b} / \mathrm{iC} 3 \mathrm{~b} / \mathrm{C} 3 \mathrm{c}$ immunostaining was quantified in sections of liver. Data are expressed as means $\pm \mathrm{SEM}(\mathbf{E}) . n=5$ mice per group (E). ${ }^{*} P<0.05$ versus tranexamic acid. Original magnification, $\times 200$ (A-D).

dead cells. ${ }^{6}$ To isolate these cells, an antibody against Ly6C, which is expressed at high levels on the surface of proinflammatory monocytes, ${ }^{33}$ was used. These cells were isolated from the livers of mice treated 24 hours earlier with APAP, a time when cytokines are highly expressed (Figure 11) and a time before phagocytosis of dead cells begins (Figure 5). Using anti-Ly6C-labeled immunomagnetic beads, Ly6C $\mathrm{C}^{\text {hi }} \mathrm{F} 4 / 80^{\text {low }}$ proinflammatory monocytes were enriched by approximately $92 \%$ from liver homogenates (Figure 12, A and B). Immunocytochemistry confirmed that these cells expressed Ly6C but not F4/80 (Figure 12, C and D). Treatment of these cells with hepatocytes made necrotic by three cycles of freeze-thaw decreased expression of the proinflammatory monocyte/macrophage marker, inducible nitric oxide synthase, and decreased expression of the proinflammatory cytokines, TNF- $\alpha$ and $\mathrm{Ccl} 2$ (Figure 12, E-G).

\section{Discussion}

Macrophages perform several key functions in the liver after APAP overdose, including production of immunomodulatory cytokines, phagocytosis of dead cell debris, and production of promitogenic growth factors. Proper regulation of these pathways is critical for repair of the liver and restoration of liver function. Studies over the past two decades have indicated that macrophage dysregulation occurs in a subset of ALF patients, leading to aberrant cytokine production and, potentially, multiorgan failure. ${ }^{9,10}$ Similarly, in an animal model of ALF, there is evidence that macrophage-dependent clearance of dead cells from the liver is impaired. ${ }^{11}$ Collectively, these studies highlight the importance of understanding the pathways that regulate macrophage function after ALF. Our studies indicate that plasmin is a central regulator of macrophage function after APAP overdose and that plasmin not only stimulates macrophage activation during the inflammatory phase, but it also stimulates resolution of inflammation during the regenerative phase.

Gao et $\mathrm{al}^{34}$ recently demonstrated that plasmin activity is increased in the liver within 6 hours after APAP treatment. At this time, Kupffer cells, the resident macrophages of the liver, become activated and secrete proinflammatory cytokines that recruit various immune cell types to the liver. ${ }^{5}$ Several recent studies have revealed that plasmin is critical for induction of cytokines and initiation of inflammation in the peritoneum, lungs, and brain. ${ }^{35-37}$ On the basis of these findings, it was examined whether plasmin is similarly required for early cytokine induction after APAP overdose. Our studies revealed that inhibition of plasmin prevented upregulation of TNF- $\alpha, \mathrm{Cxcl} 1, \mathrm{Cxcl} 2$, and $\mathrm{Ccl} 2$ by 6 hours after APAP treatment. Interestingly, this effect was lost by 24 hours after APAP treatment, indicating that additional factors maintain cytokine production at later times. Alternatively, it is possible that plasmin-dependent activation of Kupffer cells produces the initial wave of cytokines, whereas proinflammatory monocytes recruited to the liver at later times maintain cytokine production, an effect that may occur independent of plasmin. 
A

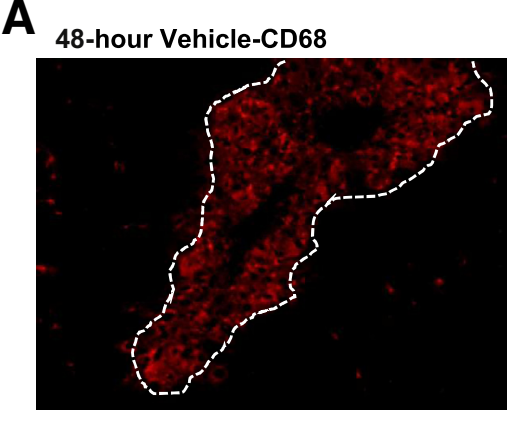

D 48-hour Vehicle-F4/80

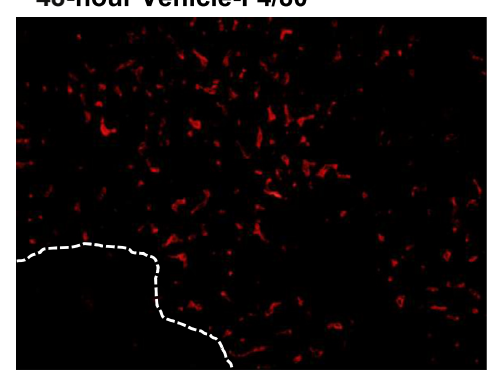

$\mathbf{F}$

72-hour Vehicle-F4/80

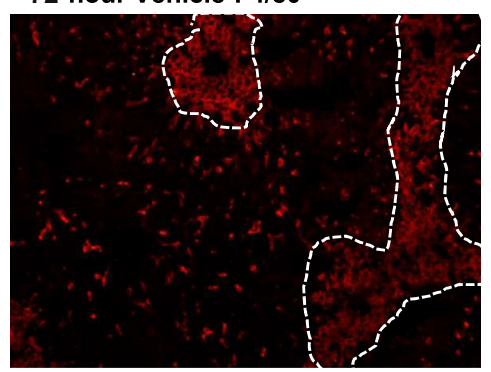

B

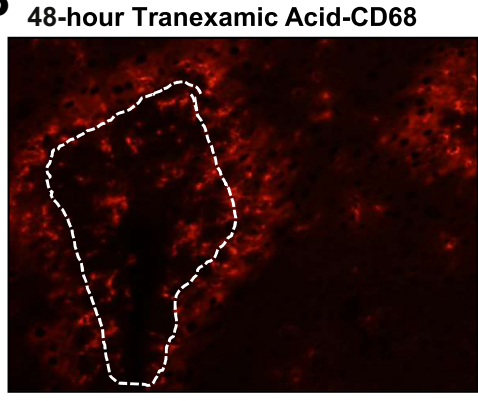

E

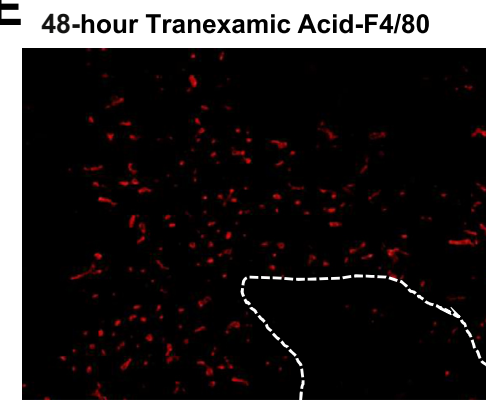

$\mathbf{G}_{72-\text { hour Tranexamic Acid-F4/80 }}$

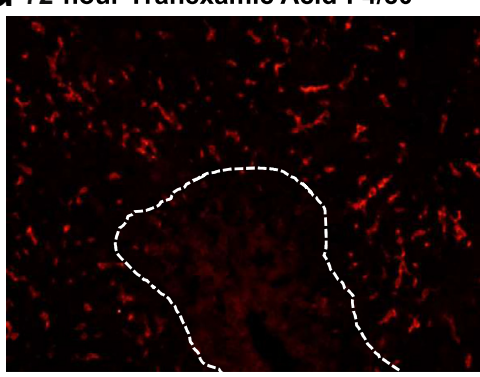

C

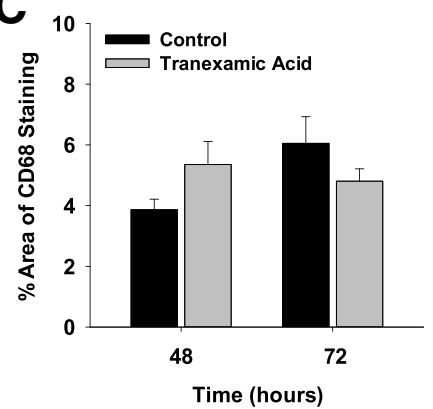

Time (hours)

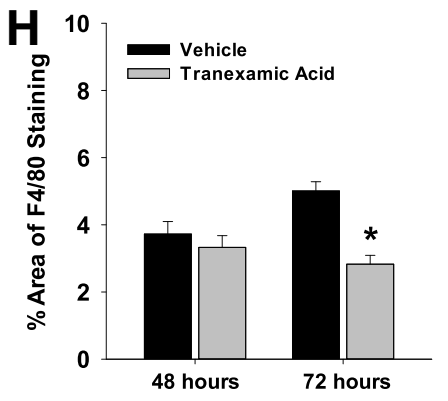

Figure 8 Mice were treated with $300 \mathrm{mg} / \mathrm{kg}$ acetaminophen, followed by treatment with tranexamic acid, as detailed in Materials and Methods. A and B: CD68 was detected by immunofluorescence. The necrotic lesions are demarcated by dashed lines. C: Area of CD68 fluorescence was quantified in sections of liver. D-G: F4/80 was detected by immunofluorescence. H: Area of F4/80 immunostaining was quantified in sections of liver. Data are expressed as means \pm SEM $(\mathbf{C}$ and $\mathbf{H}) . n=5$ mice per group $(\mathbf{C}$ and $\mathbf{H}) .{ }^{*} P<0.05$ versus vehicle. Original magnification, $\times 200(\mathbf{A}, \mathbf{B}$, and $\mathbf{D}-\mathbf{G})$.

Studies using RAW264.7 cells and monocyte-derived macrophages have revealed that plasmin directly stimulates macrophage activation. ${ }^{26,38,39}$ On the basis of these findings, we tested the hypothesis that plasmin directly activates Kupffer cells. Treatment of Kupffer cells or bone marrow-derived macrophages with plasmin increased production of several cytokines. Up-regulation of these cytokines required NF- $\mathrm{BB}$ and plasmin enzyme activity, similar to what was reported in monocyte-derived macrophages. ${ }^{38}$ By contrast to monocyte-derived macrophages, ${ }^{26}$ however, this occurred independent of annexin A2, a putative receptor for plasmin. Although it is not fully clear why this difference exists, it is possible that the mechanism by which plasmin activates macrophages may depend on the source of macrophages. Studies have also suggested that PAR-1 is activated on macrophages by plasmin. ${ }^{25}$ Our studies revealed, however, that PAR-1 was dispensable for macrophage activation by plasmin after APAP overdose. In addition to annexin A2 and PAR-1, the receptors enolase-1 and plasminogen receptor (KT) bind to plasmin and facilitate signaling in macrophages. ${ }^{13,40-42}$ It is possible that plasmin stimulates production of proinflammatory cytokines after APAP overdose through activation of one of these receptors.

It has been proposed that HMGB1 is critical for triggering macrophage activation after tissue injury. In support of this, deficiency in HMGB1 reduces proinflammatory cytokine induction in the liver after ischemia-reperfusion or APAP overdose. ${ }^{27}$ Surprisingly, however, in our studies, treatment of bone marrow-derived macrophages or Kupffer cells with recombinant HMGB1, ranging in concentration from 50 to $500 \mathrm{ng} / \mathrm{mL}$, or necrotic hepatocytes did not increase expression of TNF- $\alpha$. These concentrations of HMGB1 are within or above the range reported in vivo. Blood levels of HMGB 1 are approximately $4 \mathrm{ng} / \mathrm{mL}$ in APAP-induced acute liver failure patients and approximately $175 \mathrm{ng} / \mathrm{mL}$ in mice treated with a high dose of APAP (ie, $530 \mathrm{mg} / \mathrm{kg}$ ). ${ }^{28}$ It is possible that HMGB1 concentrations are higher in the liver, where Kupffer cells reside, and that the concentrations tested in our studies were below this level. Studies have 
A Gating Strategy

Liver

Nonparenchymal $\longrightarrow \mathrm{CD} 45 \longrightarrow \mathrm{CD} 68 \longrightarrow \mathrm{F} 4 / 80$

Cells

B

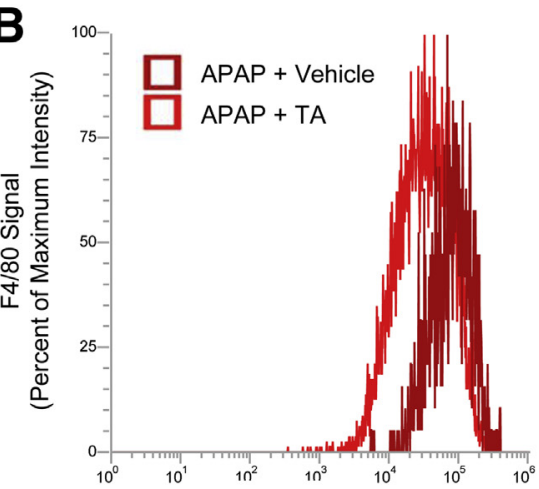

D

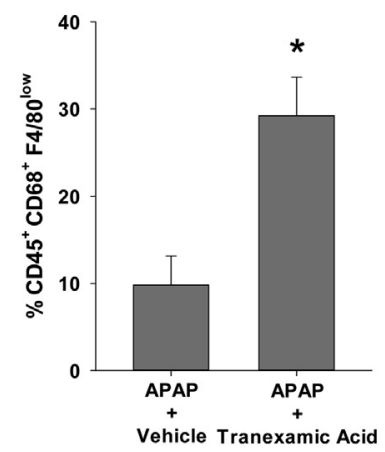

C

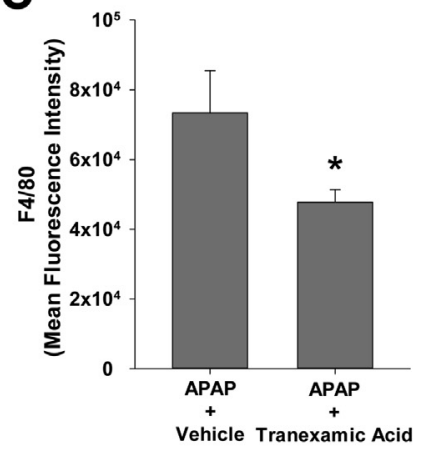

E

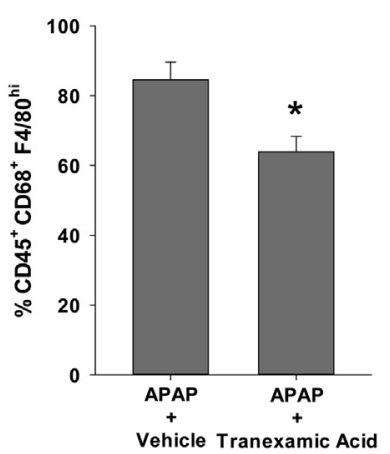

Figure 9 Mice were treated with $300 \mathrm{mg} / \mathrm{kg}$ acetaminophen (APAP), followed by treatment with tranexamic acid (TA), as detailed in Materials and Methods. After 72 hours, the livers were digested and CD45, CD68, and $\mathrm{F} 4 / 80$ were detected in the nonparenchymal cell fraction by flow cytometry. A: The gating strategy used for flow cytometry. B and C: The intensity of F4/80 staining within the $\mathrm{CD} 45^{+} \mathrm{CD}_{68}{ }^{+}$population was quantified. $\mathbf{D}$ and $\mathbf{E}$ : The percentage of $\mathrm{F} 4 / 80^{\text {low }}$ and $\mathrm{F} 4 / 80^{\mathrm{hi}}$ macrophages within the $\mathrm{CD} 45^{+} \mathrm{CD} 68^{+}$population was quantified. Data are expressed as means \pm SEM $(\mathbf{C}-\mathbf{E}) . n=3$ mice per group $(\mathbf{C}-\mathbf{E}) .{ }^{*} P<0.05$ versus APAP + vehicle. shown that HMGB1 activates macrophages in the $\mu \mathrm{g} / \mathrm{mL}$ range. ${ }^{43,44}$ Alternatively, it is possible that specific posttranslational modifications occur on HMGB1 that modify its potency after APAP overdose. Studies have shown that the oxidation-reduction status of HMGB1 heavily dictates the bioactivity of this protein. ${ }^{45}$ Furthermore, studies have demonstrated that HMGB1 can be acetylated and phosphorylated. ${ }^{46}$ These aspects of HMGB1 biology were not investigated in our studies. An additional possibility, revealed by our studies, is that HMGB1 synergistically enhances activation of Kupffer cells by plasmin, and that both mediators are needed to fully activate macrophages.

The studies described above showed that plasmin activation of macrophages was greatly enhanced by
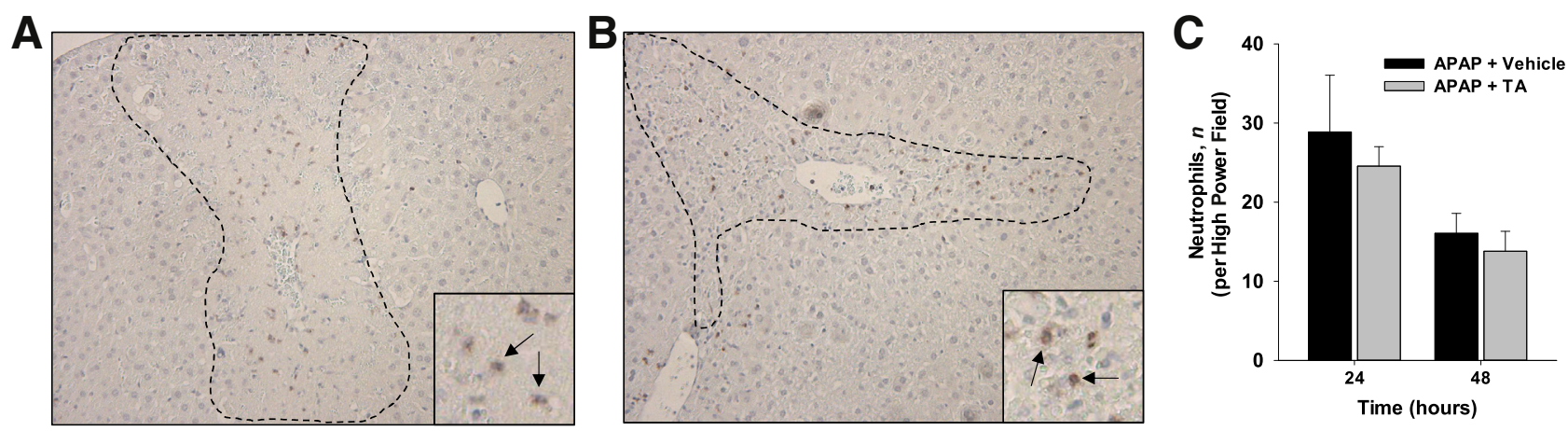

Figure 10 Mice were treated with $300 \mathrm{mg} / \mathrm{kg}$ acetaminophen (APAP), followed by treatment with tranexamic acid (TA) for 24 and 48 hours, as detailed in Materials and Methods. A and B: $\mathrm{Ly}_{6} \mathrm{G}^{+}$neutrophils were detected in liver sections from mice treated 24 hours earlier with either APAP and water (A) or APAP and tranexamic acid (B). The necrotic lesions are demarcated by dashed lines. Insets show images are higher magnification, with neutrophils indicated by arrows. C: The number of neutrophils was quantified. Data are expressed as means \pm SEM (C). $n=5$ mice per group (C). Original magnification: $\times 100(\mathbf{A}$ and B, main images); $\times 400$ (A and B, insets). 

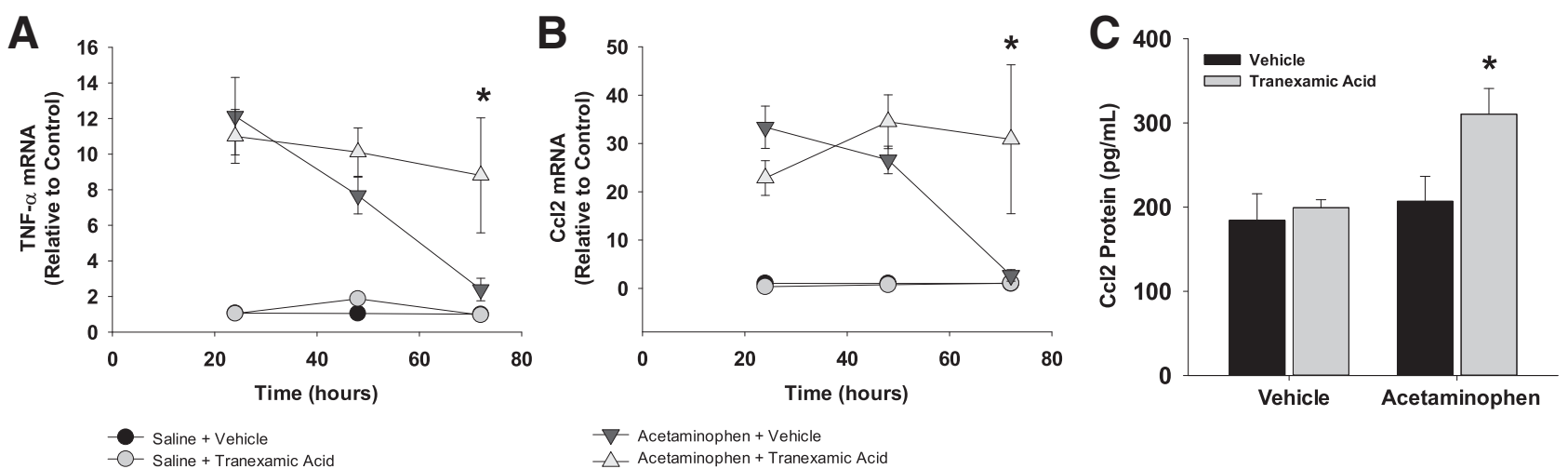

Figure 11 Mice were treated with $300 \mathrm{mg} / \mathrm{kg}$ acetaminophen, followed by treatment with tranexamic acid, as detailed in Materials and Methods. A and B: Tumor necrosis factor (TNF) $-\alpha$ and chemokine (C-C motif) ligand (Ccl2) mRNAs were quantified in the liver. C: Ccl2 protein was quantified in the serum. Data are expressed as means \pm SEM $(\mathbf{A}-\mathbf{C}) . n=5$ mice per group $(\mathbf{A}-\mathbf{C}) .{ }^{*} P<0.05$ versus acetaminophen + vehicle.

concentrations of HMGB1 that were without effect alone. Similar to our studies, it was reported that HMGB1 synergistically enhances lipopolysaccharide-induced cytokine production by macrophages. ${ }^{47,48}$ In this context, HMGB1 delivers extracellular lipopolysaccharide to the cytosol of cells, where it stimulates pyroptosis by a caspase11-dependent manner. ${ }^{21}$ Similarly, HMGB1 interacts with extracellular DNA and CXCL12 to enhance signaling through toll-like receptor 9 and $\mathrm{C}-\mathrm{X}-\mathrm{C}$ chemokine receptor type 4 , respectively. ${ }^{49,50}$ Our studies did not fully elucidate the molecular mechanism by which HMGB1 enhances activation of macrophages by plasmin. One intriguing possibility, however, is that plasmin cleaves HMGB1, which modifies its potency. It was previously reported that plasmin cleaves HMGB1; however, whether this affected its ability to activate either toll-like receptor 4 or receptor for advanced glycation endproducts was not investigated. ${ }^{51}$ Others have identified proteases that cleave HMGB1; however, in these instances, cleavage of HMGB1 decreased its activity. ${ }^{52-54}$

Paradoxically, although plasmin was critical for early cytokine induction, it was also important for resolution of inflammation at later times. A similarly important role for plasmin was recently reported in a mouse model of peritonitis, in which plasmin was critical for induction of the antiinflammatory protein, annexin A1 ${ }^{16}$ Our studies suggest that
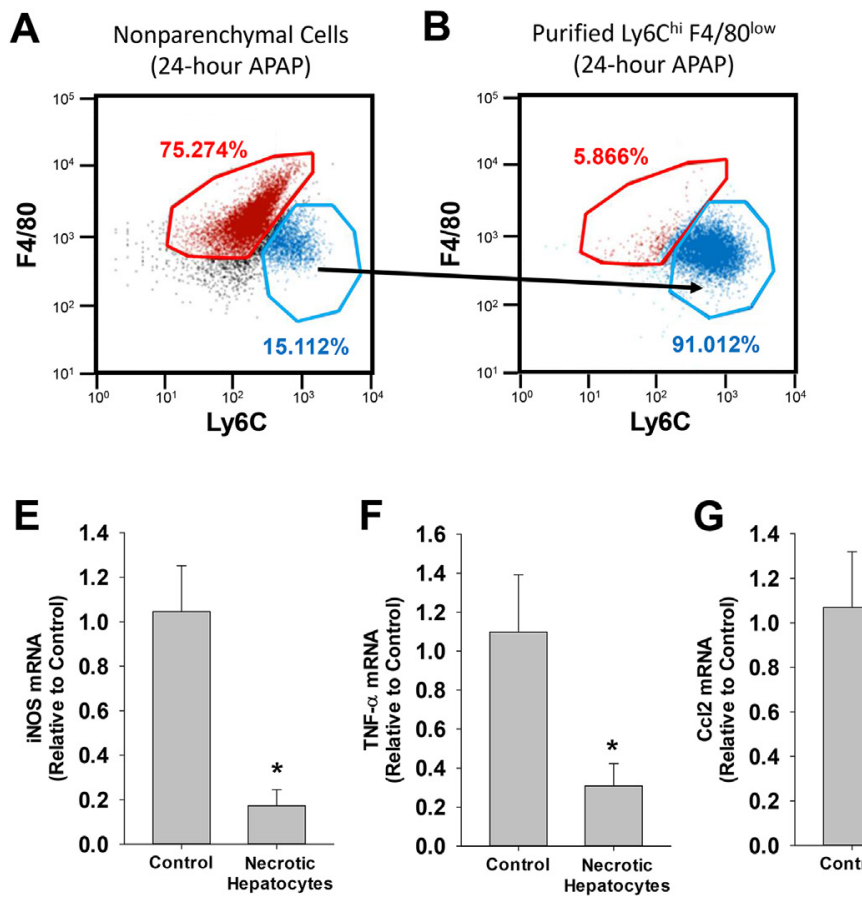

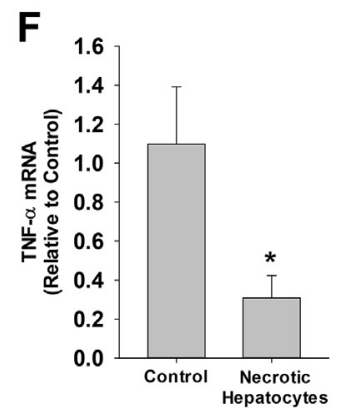

C

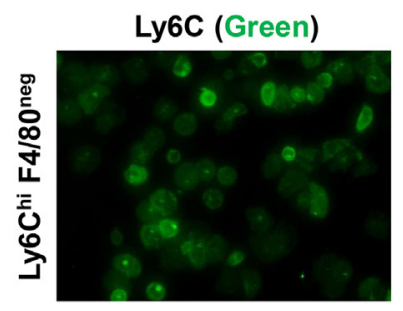

D

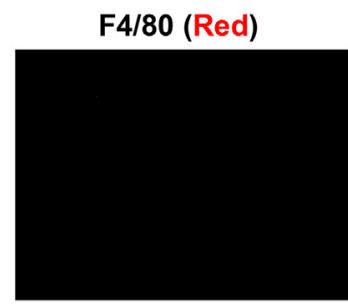

Figure 12 Mice were treated with $300 \mathrm{mg} / \mathrm{kg}$ acetaminophen (APAP). After 24 hours, Ly6 $\mathrm{C}^{\mathrm{hi}} \mathrm{F} 4 / 80^{\text {neg }}$ monocytes were isolated from the livers of mice by using immunomagnetic beads. A and B: Nonparenchymal cells (A) and purified Ly6 $\mathrm{C}^{\mathrm{hi}} \mathrm{F} 4 / 80^{\text {neg }}$ cells (B) were analyzed by flow cytometry. $\mathbf{C}$ and $\mathbf{D}$ : Immunofluorescence was used to detect Ly6C (green; C) and F4/80 (red; D) in cultured Ly6 $\mathrm{C}^{\mathrm{hi}} \mathrm{F} 4 / 80^{\text {neg }}$ monocytes. E-G: Ly6 $\mathrm{C}^{\text {hi }} \mathrm{F} 4 / 80^{\text {neg }}$ cells were treated with control media or media containing necrotic hepatocytes. Data are expressed as means \pm SEM $(\mathbf{E}-\mathbf{G}) . n=3(\mathbf{E}-\mathbf{G}) .{ }^{*} P<0.05$ versus control. Original magnification, $\times 400$ (C and D). $\mathrm{Ccl}$, chemokine (C-C motif) ligand; iNOS, inducible nitric oxide synthase; TNF$\alpha$, tumor necrosis factor- $\alpha$. 
plasmin stimulated resolution of inflammation after APAP overdose indirectly through the modulation of macrophage trafficking. After APAP treatment, necrotic lesions fill with $\mathrm{CD}^{+} 8^{+}$monocytes/macrophages by 48 hours (Figure 8A). Although the inhibition of plasmin did not affect accumulation of these cells in the liver, it prevented trafficking of these cells into the necrotic lesions. This was reported previously in plasminogen knockout mice subjected to a stab wound in the liver. ${ }^{18}$ One possible explanation for failed trafficking of macrophages is that fibrin, localized within the lesions, produces a physical barrier that prevents macrophage penetration into the lesion. It was recently demonstrated, however, that fibrinogen-deficient mice show a similar defect in the removal of necrotic cells from the liver after APAP overdose, suggesting that impaired clearance of fibrin is not the cause of impaired macrophage trafficking. ${ }^{55}$ Another possible explanation is that plasmin activates matrix metalloproteinases (MMPs) that are needed for macrophage migration through the cellular debris and extracellular matrix within necrotic lesions. Plasmin activates several MMPs, including MMP2, MMP9, and MMP12; and the hepatic activity of these MMPs is increased in APAP-treated mice. ${ }^{35,56,57}$ Furthermore, it was previously shown by Gao et $\mathrm{al}^{34}$ that excessive plasmin activity after APAP overdose in mice results in compromised sinusoidal vascular integrity through the detachment of sinusoidal endothelial cells. This was prevented by inhibition of plasmin with tranexamic acid. ${ }^{34}$ It is possible that the loss of sinusoidal integrity is important for trafficking macrophages into the necrotic lesions and for the direct physical interaction between macrophages and necrotic hepatocytes. Interestingly, although macrophage trafficking was impaired, neutrophil trafficking into the necrotic lesions was unaffected by plasmin inhibition.

Diminished trafficking of monocytes/macrophages into the lesions prevented phagocytic clearance of dead cell debris, which our results indicate allowed for the persistence of proinflammatory monocytes/macrophages. After APAP overdose, proinflammatory monocytes are rapidly recruited to the liver. As necrotic cell debris are removed from the liver, these cells mature into Ly6 $\mathrm{C}^{\text {low }} \mathrm{F} 4 / 80^{\mathrm{hi}}$ macrophages that express reduced levels of proinflammatory cytokines. Although the factors that stimulate differentiation of proinflammatory monocytes into Ly $6 \mathrm{C}^{\text {low }} \mathrm{F} 4 / 80^{\text {hi }}$ macrophages in the liver after APAP overdose are not known, our studies suggest that phagocytosis of necrotic hepatocytes stimulates this process. In support of this, incubation of $\mathrm{Ly} 6 \mathrm{C}^{\text {hi }} \mathrm{F} 4 / 80^{\text {low }}$ monocytes, isolated from the livers of APAP-treated mice, with necrotic hepatocytes was sufficient to decrease expression of proinflammatory cytokines. This would explain the lack of F4/80 induction on macrophages and the persistence of cytokine expression in mice cotreated with APAP and the plasmin inhibitor, tranexamic acid. In other words, when plasmin was inhibited, monocytes were incapable of entering the lesions and phagocytosing dead cell debris, which prevented maturation of these cells into F4/80-expressing macrophages that express reduced levels of cytokines.
As mentioned, several studies have indicated that macrophage dysfunction occurs in ALF, which, in patients, leads to sustained cytokine production, and in animal models, leads to the failed clearance of necrotic cells. ${ }^{9-11}$ Interestingly, it was recently reported that plasminogen deficiency occurs in patients with ALF. ${ }^{58}$ On the basis of our findings, it is possible that plasminogen deficiency could explain, in part, sustained cytokine production and failed phagocytosis in ALF. Therefore, restoration of plasminogen levels in these patients may restore macrophage function, leading to enhanced phagocytosis and diminished cytokine production. Additional studies are needed, however, to test this possibility.

Collectively, our studies indicate that plasmin not only stimulates cytokine production by Kupffer cells, but it also promotes resolution of inflammation after APAP overdose. It promotes resolution of inflammation by promoting trafficking of monocytes/macrophages into necrotic lesions, where these cells phagocytose dead cell debris, a process that stimulates their maturation and differentiation.

\section{Acknowledgment}

We thank Dr. Russell S. Taichman (University of Michigan, Ann Arbor, MI) for the generous gift of annexin A2 knockout mice.

\section{References}

1. Nourjah P, Ahmad SR, Karwoski C, Willy M: Estimates of acetaminophen (Paracetomal)-associated overdoses in the United States. Pharmacoepidemiol Drug Saf 2006, 15:398-405

2. Lee WM, Squires RH Jr, Nyberg SL, Doo E, Hoofnagle JH: Acute liver failure: summary of a workshop. Hepatology 2008, 47: 1401-1415

3. Rumack BH, Peterson RC, Koch GG, Amara IA: Acetaminophen overdose. 662 cases with evaluation of oral acetylcysteine treatment. Arch Intern Med 1981, 141:380-385

4. Smilkstein MJ, Knapp GL, Kulig KW, Rumack BH: Efficacy of oral $\mathrm{N}$-acetylcysteine in the treatment of acetaminophen overdose: analysis of the national multicenter study (1976 to 1985). N Engl J Med 1988, 319:1557-1562

5. Fisher JE, McKenzie TJ, Lillegard JB, Yu Y, Juskewitch JE, Nedredal GI, Brunn GJ, Yi ES, Malhi H, Smyrk TC, Nyberg SL: Role of Kupffer cells and toll-like receptor 4 in acetaminopheninduced acute liver failure. J Surg Res 2013, 180:147-155

6. Holt MP, Cheng L, Ju C: Identification and characterization of infiltrating macrophages in acetaminophen-induced liver injury. J Leukoc Biol 2008, 84:1410-1421

7. Dambach DM, Watson LM, Gray KR, Durham SK, Laskin DL: Role of CCR2 in macrophage migration into the liver during acetaminophen-induced hepatotoxicity in the mouse. Hepatology 2002, 35:1093-1103

8. Zigmond E, Samia-Grinberg S, Pasmanik-Chor M, Brazowski E, Shibolet O, Halpern Z, Varol C: Infiltrating monocyte-derived macrophages and resident Kupffer cells display different ontogeny and functions in acute liver injury. J Immunol 2014, 193:344-353

9. Berry PA, Antoniades CG, Hussain MJ, McPhail MJ, Bernal W, Vergani D, Wendon JA: Admission levels and early changes in serum interleukin-10 are predictive of poor outcome in acute liver failure and decompensated cirrhosis. Liver Int 2010, 30:733-740 
10. Antoniades CG, Berry PA, Wendon JA, Vergani D: The importance of immune dysfunction in determining outcome in acute liver failure. J Hepatol 2008, 49:845-861

11. Bhushan B, Walesky C, Manley M, Gallagher T, Borude P, Edwards G, Monga SP, Apte U: Pro-regenerative signaling after acetaminophen-induced acute liver injury in mice identified using a novel incremental dose model. Am J Pathol 2014, 184:3013-3025

12. Ploplis VA, French EL, Carmeliet P, Collen D, Plow EF: Plasminogen deficiency differentially affects recruitment of inflammatory cell populations in mice. Blood 1998, 91:2005-2009

13. Wygrecka M, Marsh LM, Morty RE, Henneke I, Guenther A, Lohmeyer J, Markart P, Preissner KT: Enolase-1 promotes plasminogen-mediated recruitment of monocytes to the acutely inflamed lung. Blood 2009, 113:5588-5598

14. Das R, Ganapathy S, Settle M, Plow EF: Plasminogen promotes macrophage phagocytosis in mice. Blood 2014, 124:679-688

15. Borg RJ, Samson AL, Au AE, Scholzen A, Fuchsberger M, Kong YY, Freeman R, Mifsud NA, Plebanski M, Medcalf RL: Dendritic cell-mediated phagocytosis but not immune activation is enhanced by plasmin. PLoS One 2015, 10:e0131216

16. Sugimoto MA, Ribeiro ALC, Costa BRC, Vago JP, Lima KM, Carneiro FS, Ortiz MMO, Lima GLN, Carmo AAF, Rocha RM, Perez DA, Reis AC, Pinho V, Miles LA, Garcia CC, Teixeira MM, Sousa LP: Plasmin and plasminogen induce macrophage reprogramming and regulate key steps of inflammation resolution via annexin A1. Blood 2017, 129:2896-2907

17. Bezerra JA, Bugge TH, Melin-Aldana H, Sabla G, Kombrinck KW, Witte DP, Degen JL: Plasminogen deficiency leads to impaired remodeling after a toxic injury to the liver. Proc Natl Acad Sci U S A 1999, 96:15143-15148

18. Kawao N, Nagai N, Okada K, Okumoto K, Ueshima S, Matsuo O: Role of plasminogen in macrophage accumulation during liver repair. Thromb Res 2010, 125:e214-e221

19. Ling Q, Jacovina AT, Deora A, Febbraio M, Simantov R, Silverstein RL, Hempstead B, Mark WH, Hajjar KA: Annexin II regulates fibrin homeostasis and neoangiogenesis in vivo. $\mathrm{J}$ Clin Invest 2004, 113:38-48

20. Griffin CT, Srinivasan Y, Zheng YW, Huang W, Coughlin SR: A role for thrombin receptor signaling in endothelial cells during embryonic development. Science 2001, 293:1666-1670

21. Deng M, Tang Y, Li W, Wang X, Zhang R, Zhang X, Zhao X, Liu J, Tang C, Liu Z, Huang Y, Peng H, Xiao L, Tang D, Scott MJ, Wang Q, Liu J, Xiao X, Watkins S, Li J, Yang H, Wang H, Chen F, Tracey KJ, Billiar TR, Lu B: The endotoxin delivery protein HMGB1 mediates caspase-11-dependent lethality in sepsis. Immunity 2018, 49:740-753.e7

22. Mochizuki A, Pace A, Rockwell CE, Roth KJ, Chow A, O'Brien KM, Albee R, Kelly K, Towery K, Luyendyk JP, Copple BL: Hepatic stellate cells orchestrate clearance of necrotic cells in a hypoxia-inducible factor-1alpha-dependent manner by modulating macrophage phenotype in mice. J Immunol 2014, 192:3847-3857

23. Kim ND, Moon JO, Slitt AL, Copple BL: Early growth response factor-1 is critical for cholestatic liver injury. Toxicol Sci 2006, 90: $586-595$

24. Schwarz H, Schmittner M, Duschl A, Horejs-Hoeck J: Residual endotoxin contaminations in recombinant proteins are sufficient to activate human CD1c + dendritic cells. PLoS One 2014, 9:e113840

25. Carmo AA, Costa BR, Vago JP, de Oliveira LC, Tavares LP, Nogueira CR, Ribeiro AL, Garcia CC, Barbosa AS, Brasil BS, Dusse LM, Barcelos LS, Bonjardim CA, Teixeira MM, Sousa LP: Plasmin induces in vivo monocyte recruitment through proteaseactivated receptor-1-, MEK/ERK-, and CCR2-mediated signaling. J Immunol 2014, 193:3654-3663

26. Laumonnier Y, Syrovets T, Burysek L, Simmet T: Identification of the annexin A2 heterotetramer as a receptor for the plasmin-induced signaling in human peripheral monocytes. Blood 2006, 107: $3342-3349$
27. Huebener P, Pradere JP, Hernandez C, Gwak GY, Caviglia JM, Mu X, Loike JD, Jenkins RE, Antoine DJ, Schwabe RF: The HMGB1/RAGE axis triggers neutrophil-mediated injury amplification following necrosis. J Clin Invest 2015, 125:539-550

28. Antoine DJ, Williams DP, Kipar A, Jenkins RE, Regan SL, Sathish JG, Kitteringham NR, Park BK: High-mobility group box-1 protein and keratin-18, circulating serum proteins informative of acetaminophen-induced necrosis and apoptosis in vivo. Toxicol Sci 2009, 112:521-531

29. Cresci GA, Allende D, McMullen MR, Nagy LE: Alternative complement pathway component factor D contributes to efficient clearance of tissue debris following acute $\mathrm{CCl}(4)$-induced injury. Mol Immunol 2015, 64:9-17

30. Arnold L, Henry A, Poron F, Baba-Amer Y, van Rooijen N, Plonquet A, Gherardi RK, Chazaud B: Inflammatory monocytes recruited after skeletal muscle injury switch into antiinflammatory macrophages to support myogenesis. J Exp Med 2007, 204:1057-1069

31. Odaka C, Mizuochi T, Yang J, Ding A: Murine macrophages produce secretory leukocyte protease inhibitor during clearance of apoptotic cells: implications for resolution of the inflammatory response. J Immunol 2003, 171:1507-1514

32. Fadok VA, Bratton DL, Konowal A, Freed PW, Westcott JY, Henson PM: Macrophages that have ingested apoptotic cells in vitro inhibit proinflammatory cytokine production through autocrine/paracrine mechanisms involving TGF-beta, PGE2, and PAF. J Clin Invest 1998, 101:890-898

33. Yang J, Zhang L, Yu C, Yang XF, Wang H: Monocyte and macrophage differentiation: circulation inflammatory monocyte as biomarker for inflammatory diseases. Biomark Res 2014, 2:1

34. Gao S, Silasi-Mansat R, Behar AR, Lupu F, Griffin CT: Excessive plasmin compromises hepatic sinusoidal vascular integrity after acetaminophen overdose. Hepatology 2018, 68 : $1991-2003$

35. Gong Y, Hart E, Shchurin A, Hoover-Plow J: Inflammatory macrophage migration requires MMP-9 activation by plasminogen in mice. J Clin Invest 2008, 118:3012-3024

36. Swaisgood CM, Aronica MA, Swaidani S, Plow EF: Plasminogen is an important regulator in the pathogenesis of a murine model of asthma. Am J Respir Crit Care Med 2007, 176:333-342

37. Hultman K, Cortes-Canteli M, Bounoutas A, Richards AT, Strickland S, Norris EH: Plasmin deficiency leads to fibrin accumulation and a compromised inflammatory response in the mouse brain. J Thromb Haemost 2014, 12:701-712

38. Syrovets T, Jendrach M, Rohwedder A, Schule A, Simmet T: Plasmin-induced expression of cytokines and tissue factor in human monocytes involves AP-1 and IKKbeta-mediated NF-kappaB activation. Blood 2001, 97:3941-3950

39. Weide I, Tippler B, Syrovets T, Simmet T: Plasmin is a specific stimulus of the 5-lipoxygenase pathway of human peripheral monocytes. Thromb Haemost 1996, 76:561-568

40. Miles LA, Dahlberg CM, Plescia J, Felez J, Kato K, Plow EF: Role of cell-surface lysines in plasminogen binding to cells: identification of alpha-enolase as a candidate plasminogen receptor. Biochemistry 1991, 30:1682-1691

41. Miles LA, Baik N, Lighvani S, Khaldoyanidi S, Varki NM, Bai H, Mueller BM, Parmer RJ: Deficiency of plasminogen receptor, PlgRKT, causes defects in plasminogen binding and inflammatory macrophage recruitment in vivo. J Thromb Haemost 2017, 15: $155-162$

42. Lighvani S, Baik N, Diggs JE, Khaldoyanidi S, Parmer RJ, Miles LA: Regulation of macrophage migration by a novel plasminogen receptor Plg-R KT. Blood 2011, 118:5622-5630

43. Abraham E, Arcaroli J, Carmody A, Wang H, Tracey KJ: HMG-1 as a mediator of acute lung inflammation. J Immunol 2000, 165: $2950-2954$

44. Andersson U, Wang H, Palmblad K, Aveberger AC, Bloom O, Erlandsson-Harris H, Janson A, Kokkola R, Zhang M, Yang H, 
Tracey KJ: High mobility group 1 protein (HMG-1) stimulates proinflammatory cytokine synthesis in human monocytes. J Exp Med 2000, 192:565-570

45. Yang H, Antoine DJ, Andersson U, Tracey KJ: The many faces of HMGB1: molecular structure-functional activity in inflammation, apoptosis, and chemotaxis. J Leukoc Biol 2013, 93:865-873

46. Ge X, Antoine DJ, Lu Y, Arriazu E, Leung TM, Klepper AL, Branch AD, Fiel MI, Nieto N: High mobility group box-1 (HMGB1) participates in the pathogenesis of alcoholic liver disease (ALD). J Biol Chem 2014, 289:22672-22691

47. Youn JH, Oh YJ, Kim ES, Choi JE, Shin JS: High mobility group box 1 protein binding to lipopolysaccharide facilitates transfer of lipopolysaccharide to CD14 and enhances lipopolysaccharide-mediated TNFalpha production in human monocytes. J Immunol 2008, 180: 5067-5074

48. Qin YH, Dai SM, Tang GS, Zhang J, Ren D, Wang ZW, Shen Q: HMGB1 enhances the proinflammatory activity of lipopolysaccharide by promoting the phosphorylation of MAPK p38 through receptor for advanced glycation end products. J Immunol 2009, 183:6244-6250

49. Tian J, Avalos AM, Mao SY, Chen B, Senthil K, Wu H, Parroche P, Drabic S, Golenbock D, Sirois C, Hua J, An LL, Audoly L, La Rosa G, Bierhaus A, Naworth P, MarshakRothstein A, Crow MK, Fitzgerald KA, Latz E, Kiener PA, Coyle AJ: Toll-like receptor 9-dependent activation by DNAcontaining immune complexes is mediated by HMGB1 and RAGE. Nat Immunol 2007, 8:487-496

50. Schiraldi M, Raucci A, Munoz LM, Livoti E, Celona B, Venereau E, Apuzzo T, De Marchis F, Pedotti M, Bachi A, Thelen M, Varani L, Mellado M, Proudfoot A, Bianchi ME, Uguccioni M: HMGB1 promotes recruitment of inflammatory cells to damaged tissues by forming a complex with CXCL12 and signaling via CXCR4. J Exp Med 2012, 209:551-563
51. Parkkinen J, Rauvala H: Interactions of plasminogen and tissue plasminogen activator (t-PA) with amphoterin: enhancement of t-PAcatalyzed plasminogen activation by amphoterin. J Biol Chem 1991, 266:16730-16735

52. Ito T, Kawahara K, Okamoto K, Yamada S, Yasuda M, Imaizumi H, Nawa Y, Meng X, Shrestha B, Hashiguchi T, Maruyama I: Proteolytic cleavage of high mobility group box 1 protein by thrombinthrombomodulin complexes. Arterioscler Thromb Vasc Biol 2008, 28:1825-1830

53. Roy A, Ganesh G, Sippola H, Bolin S, Sawesi O, Dagalv A, Schlenner SM, Feyerabend T, Rodewald HR, Kjellen L, Hellman L, Abrink M: Mast cell chymase degrades the alarmins heat shock protein 70, biglycan, HMGB1, and interleukin-33 (IL-33) and limits danger-induced inflammation. J Biol Chem 2014, 289:237-250

54. Marchetti C, Di Carlo A, Facchiano F, Senatore C, De Cristofaro R, Luzi A, Federici M, Romani M, Napolitano M, Capogrossi MC, Germani A: High mobility group box 1 is a novel substrate of dipeptidyl peptidase-IV. Diabetologia 2012, 55:236-244

55. Kopec AK, Joshi N, Cline-Fedewa H, Wojcicki AV, Ray JL, Sullivan BP, Froehlich JE, Johnson BF, Flick MJ, Luyendyk JP: Fibrin(ogen) drives repair after acetaminophen-induced liver injury via leukocyte alphaMbeta2 integrin-dependent upregulation of Mmp12. J Hepatol 2017, 66:787-797

56. Monea S, Lehti K, Keski-Oja J, Mignatti P: Plasmin activates pro-matrix metalloproteinase-2 with a membrane-type 1 matrix metalloproteinasedependent mechanism. J Cell Physiol 2002, 192:160-170

57. Ito Y, Abril ER, Bethea NW, McCuskey RS: Inhibition of matrix metalloproteinases minimizes hepatic microvascular injury in response to acetaminophen in mice. Toxicol Sci 2005, 83:190-196

58. Lisman T, Bakhtiari K, Adelmeijer J, Meijers JC, Porte RJ, Stravitz RT: Intact thrombin generation and decreased fibrinolytic capacity in patients with acute liver injury or acute liver failure. J Thromb Haemost 2012, 10:1312-1319 